\title{
Regional Dynamic Sea Level Simulated in the CMIP5 and CMIP6 Models: Mean Biases, Future Projections, and Their Linkages
}

\author{
KEWEI LyU AND XUEBIN ZHANG \\ Centre for Southern Hemisphere Oceans Research, CSIRO Oceans and Atmosphere, Hobart, Tasmania, Australia \\ JOHN A. CHURCH \\ Climate Change Research Centre, University of New South Wales, Sydney, New South Wales, Australia
}

(Manuscript received 31 December 2019, in final form 28 April 2020)

\begin{abstract}
The ocean dynamic sea level (DSL) is an important component of regional sea level projections. In this study, we analyze mean states and future projections of the DSL from the global coupled climate models participating in phase 5 and phase 6 of the Coupled Model Intercomparison Project (CMIP5 and CMIP6, respectively). Despite persistent biases relative to observations, both CMIP5 and CMIP6 simulate the mean sea level reasonably well. The equatorward bias of the Southern Hemisphere westerly wind stress is reduced from CMIP5 to CMIP6, which improves the simulated mean sea level in the Southern Ocean. The CMIP5 and CMIP6 DSL projections exhibit very similar features and intermodel uncertainties. With several models having a notably high climate sensitivity, CMIP6 projects larger DSL changes in the North Atlantic and Arctic associated with a larger weakening of the Atlantic meridional overturning circulation (AMOC). We further identify linkages between model mean states and future projections by looking for their intermodel relationships. The common cold-tongue bias leads to an underestimation of DSL rise in the western tropical Pacific. Models with their simulated midlatitude westerly winds located more equatorward tend to project larger DSL changes in the Southern Ocean and North Pacific. In contrast, a more equatorward location of the North Atlantic westerly winds or a weaker AMOC under current climatology is associated with a smaller weakening of the AMOC and weaker DSL changes in the North Atlantic and coastal Arctic. Our study provides useful emergent constraints for DSL projections and highlights the importance of reducing model mean-state biases for future projections.
\end{abstract}

\section{Introduction}

As one of the most severe consequences of climate change, sea level rise increases the risks to coastal environments and communities from coastal hazards such as destructive storm surge, flooding, and erosion (Oppenheimer et al. 2019). Global sea level rise is mainly caused by two processes: 1 ) the thermal expansion of seawater as the ocean absorbs most of the heat stored in the climate system from anthropogenic warming and 2) the addition of water to the ocean mainly from the mass loss of land ice, including glaciers and ice sheets (Church et al. 2013). The projected sea level rise is spatially nonuniform, which means the local sea level could depart significantly from the global mean. In this study, we focus on ocean dynamic sea level

\footnotetext{
Corresponding author: Kewei Lyu, kewei.lyu@csiro.au
}

(DSL) determined jointly by ocean density and circulation, defined as the local height of the sea surface above the geoid with zero global mean (Gregory et al. 2019).

The time-varying DSL essentially reflects the redistributions of heat, salt, and mass in the ocean, modulated by the natural climate variability and extreme weather conditions as well as long-term climate change. Projections of the long-term DSL changes under anthropogenic forcing rely on global coupled climate models to simulate ocean dynamical adjustments to the changing radiative forcing. From earlier versions of climate models to those participating in the recent phase 3 and phase 5 of the Coupled Model Intercomparison Project (CMIP3 and CMIP5, respectively), some common basin-scale features for the DSL projections have gradually emerged in specific regions like the Arctic, the Southern Ocean, the North Atlantic, and the North Pacific (Bryan 1996; Gregory and Lowe 2000; Gregory 
et al. 2001; Suzuki et al. 2005; Lowe and Gregory 2006; Landerer et al. 2007; Meehl et al. 2007; Yin et al. 2009, 2010; Pardaens et al. 2011; Suzuki and Ishii 2011; Yin 2012; Zhang et al. 2014). Despite these common features, the DSL projections from the individual models generally do not agree in detail and magnitude (e.g., Carson et al. 2019). There are considerable intermodel differences, especially in regions where large DSL changes are projected, although the intermodel spread was somewhat reduced from CMIP3 to CMIP5 (Bouttes et al. 2012; Church et al. 2013). It has been suggested that the uncertainties in projected changes in air-sea fluxes and ocean model subgrid parameters are two important causes of the intermodel spread in the DSL projections (Bouttes and Gregory 2014; Huber and Zanna 2017).

The reliability of future climate and sea level projections depends on the climate models' fidelity in simulating a realistic climate system. The climate models exhibit considerable differences in their simulations of present-day mean states and suffer from various biases relative to the available observations (Flato et al. 2013). For example, climate models have shown a persistent cold-tongue bias and double intertropical convergence zone (ITCZ) problem in the tropical Pacific (Li and Xie 2014). In the tropical regions, the biases in the mean sea level are generally consistent with the surface wind stress biases (Lee et al. 2013; Landerer et al. 2014). In the midlatitude Southern Hemisphere, most climate models simulate an equatorward bias in the location of the westerly winds relative to the observations (Fyfe and Saenko 2006; Russell et al. 2006; Swart and Fyfe 2012; Bracegirdle et al. 2013), which also leads to an equatorward bias in the location of the boundary between the subtropical gyres and the Antarctic Circumpolar Current (ACC) (Lyu et al. 2020). The simulated Southern Ocean water masses are located at lighter densities than observed (Sallée et al. 2013). Model mean biases such as those mentioned above also affect model simulations of the internal climate variability, such as the Indian Ocean dipole (IOD) (Cai and Cowan 2013), El Niño-Southern Oscillation (ENSO) (Ham and Kug 2015), and the interdecadal Pacific oscillation (IPO) (Lyu et al. 2016).

The model mean-state biases might provide some context for the interpretations of uncertainty in future climate projections. For example, bias correction approaches have been used to reduce the effect of model biases on the tropical Pacific warming patterns, as well as precipitation and circulation changes (Brown et al. 2015; Huang and Ying 2015; Li et al. 2016). Models with a larger equatorward bias in the position of the Southern Hemisphere westerly winds tend to project a larger future poleward shift of the westerly winds (Kidston and
Gerber 2010; Bracegirdle et al. 2013). Most climate models simulate a less stratified ocean than the real ocean, implying that these models may overestimate ocean heat uptake and underestimate surface warming (Kuhlbrodt and Gregory 2012). Working with the CMIP3 model ensemble, Yin et al. (2010) showed that after excluding models in which the mean sea level simulations have large differences from the observations, the subset ensemble of remaining models has better agreement on regional DSL projections than the full ensemble (Meehl et al. 2007). However, it remains unclear whether and how regional DSL projections depend on model simulations of the present mean state. Identifying such connections would be helpful for assessing to what extent the uncertainties in regional DSL projections can be related to the uncertainties in model mean-state simulations. Also, how some types of model mean biases may affect regional DSL projections is still unknown. To our knowledge, this is the first study trying to relate intermodel uncertainties in DSL projections to diversities in model mean-state simulations and to explore possible biases in the projections considering mean-state biases.

Phase 6 of the Coupled Model Intercomparison Project (CMIP6; Eyring et al. 2016) brings together the state-ofthe-art climate models and provides valuable multimodel simulations, which are essential to reassess the climate system response to the anthropogenic forcing and to update future climate projections. In this study, we first evaluate model simulations of the mean sea level against the observations to see if biases in mean sea level have been reduced from CMIP5 to CMIP6 (section 3). We then examine whether the CMIP6 DSL projections differ from the CMIP5 projections (section 4). Finally, we use a large ensemble of the combined CMIP5 and CMIP6 models to identify intermodel relationships between model mean-state simulations and future projections (section 5).

\section{Climate model and observational data}

In this study, 39 CMIP6 models (Table 1) and 37 CMIP5 models (Table 2) with sea surface height data available are analyzed. Only one realization from each model is used so each model is given equal weight in the multimodel analysis. Model outputs of sea surface height from CAMS-CSM1.0, GISS-E2.1-G, and MIROC5 models need to be converted into the effective sea level by removing the inverse barometer effect from sea ice (Griffies et al. 2016). The DSL is derived from model sea surface height above the geoid by removing its timedependent global mean. The observed mean ocean dynamic topography derived from satellite data and drifter trajectories over 1992-2012 (Maximenko et al. 2009) is 
TABLE 1. List of 39 CMIP6 models used in this study. The ECS values are from Zelinka et al. (2020).

\begin{tabular}{|c|c|c|c|c|c|}
\hline No. & Model name & Ocean grids & $\operatorname{ECS}\left({ }^{\circ} \mathrm{C}\right)$ & DSL projection & AMOC \\
\hline 1 & ACCESS-CM2 & $360 \times 300$ & 4.7 & $\checkmark$ & $\checkmark$ \\
\hline 2 & ACCESS-ESM1.5 & $360 \times 300$ & 3.8 & $\checkmark$ & $\checkmark$ \\
\hline 3 & BCC-CSM2-MR & $360 \times 232$ & 3.02 & $\checkmark$ & \\
\hline 4 & CanESM5 & $360 \times 291$ & 5.64 & $\checkmark$ & $\checkmark$ \\
\hline 5 & CAMS-CSM1.0 & $360 \times 200$ & 2.29 & $\checkmark$ & \\
\hline 6 & CESM2 & $320 \times 384$ & 5.15 & $\checkmark$ & $\checkmark$ \\
\hline 7 & CESM2-WACCM & $320 \times 384$ & 4.68 & $\checkmark$ & $\checkmark$ \\
\hline 8 & CIESM & $320 \times 384$ & & $\checkmark$ & \\
\hline 9 & CNRM-CM6.1 & $362 \times 294$ & 4.90 & $\checkmark$ & $\checkmark$ \\
\hline 10 & CNRM-CM6.1-HR & $1442 \times 1050$ & 4.33 & $\checkmark$ & $\checkmark$ \\
\hline 11 & CNRM-ESM2.1 & $362 \times 294$ & 4.79 & $\checkmark$ & $\checkmark$ \\
\hline 12 & EC-Earth3 & $362 \times 292$ & 4.10 & $\checkmark$ & \\
\hline 13 & EC-Earth3-Veg & $362 \times 292$ & 4.33 & $\checkmark$ & \\
\hline 14 & FGOALS-g3 & $360 \times 218$ & & $\checkmark$ & \\
\hline 15 & FIO-ESM-2.0 & $320 \times 384$ & & $\checkmark$ & \\
\hline 16 & GISS-E2.1-G & $288 \times 180$ & 2.71 & $\checkmark$ & \\
\hline 17 & HadGEM3-GC31-LL & $360 \times 330$ & 5.55 & $\checkmark$ & $\checkmark$ \\
\hline 18 & INM-CM4.8 & $360 \times 318$ & 1.83 & $\checkmark$ & $\checkmark$ \\
\hline 19 & INM-CM5.0 & $720 \times 720$ & & $\checkmark$ & $\checkmark$ \\
\hline 20 & IPSL-CM6A-LR & $362 \times 332$ & 4.56 & $\checkmark$ & \\
\hline 21 & MIROC6 & $360 \times 256$ & 2.60 & $\checkmark$ & \\
\hline 22 & MPI-ESM1.2-HR & $802 \times 404$ & 2.98 & $\checkmark$ & $\checkmark$ \\
\hline 23 & MPI-ESM1.2-LR & $256 \times 220$ & & $\checkmark$ & $\checkmark$ \\
\hline 24 & MRI-ESM2.0 & $360 \times 363$ & 3.13 & $\checkmark$ & $\checkmark$ \\
\hline 25 & NESM3 & $362 \times 292$ & 4.77 & $\checkmark$ & \\
\hline 26 & NorESM2-LM & $360 \times 385$ & 2.56 & $\checkmark$ & $\checkmark$ \\
\hline 27 & NorESM2-MM & $360 \times 385$ & & $\checkmark$ & \\
\hline 28 & UKESM1.0-LL & $360 \times 330$ & 5.36 & $\checkmark$ & $\checkmark$ \\
\hline 29 & BCC-ESM1 & $360 \times 232$ & 3.26 & & \\
\hline 30 & CESM2-FV2 & $320 \times 384$ & & & \\
\hline 31 & CESM2-WACCM-FV2 & $320 \times 384$ & & & \\
\hline 32 & E3SM-1.0 & Unstructured & 5.31 & & \\
\hline 33 & E3SM-1.1 & Unstructured & & & \\
\hline 34 & FGOALS-f3-L & $360 \times 218$ & 2.98 & & \\
\hline 35 & GFDL-CM4 & $1440 \times 1080$ & 3.89 & & \\
\hline 36 & GFDL-ESM4 & $720 \times 576$ & & & \\
\hline 37 & GISS-E2.1-H & $144 \times 90$ & 3.12 & & \\
\hline 38 & NorCPM1 & $320 \times 384$ & & & \\
\hline 39 & SAM0-UNICON & $320 \times 384$ & 3.72 & & \\
\hline
\end{tabular}

used to evaluate model simulations of mean sea level. As a primary driver for the upper-ocean circulation and regional sea level, the surface zonal wind stress is also examined to explore possible connections between model biases in the simulated mean sea level and surface zonal wind stress. The simulated surface zonal wind stress is compared with the surface wind stress climatology from the Scatterometer Climatology of Ocean Winds (SCOW) product based on satellite Quick Scatterometer (QuikSCAT) measurements from September 1999 to October 2009 (Risien and Chelton 2008). The latest reanalysis, ERA5 (Hersbach and Dee 2016), available over 1979-2018 produced by the European Centre for Medium-Range Weather Forecasts (ECMWF), is also used to assess the sensitivity of model biases to the base period over which the climatology is defined. The observed mean fields are compared to the time-mean fields from the CMIP5 and CMIP6 historical simulations averaged over 1986-2005 (i.e., the last two decades of the CMIP5 historical runs). We regrid all data onto a common global grid of $0.5^{\circ}$ latitude $\times 0.5^{\circ}$ longitude for multimodel analyses and intermodel comparisons.

The CMIP6 climate projections are driven by a new set of future climate scenarios based on the Shared Socioeconomic Pathway (SSP; Riahi et al. 2017). The new SSP-based scenarios have their own narratives and thus exhibit somewhat different emission trajectories and land use changes from the previous representative concentration pathway (RCP; van Vuuren et al. 2011) 
TABLE 2. List of 37 CMIP5 models used in this study. The ECS values are from Zelinka et al. (2020).

\begin{tabular}{|c|c|c|c|c|c|}
\hline No. & Model name & Ocean grids & $\operatorname{ECS}\left({ }^{\circ} \mathrm{C}\right)$ & DSL projection & AMOC \\
\hline 1 & ACCESS1.0 & $360 \times 300$ & 3.85 & $\checkmark$ & $\checkmark$ \\
\hline 2 & ACCESS1.3 & $360 \times 300$ & 3.55 & $\checkmark$ & $\checkmark$ \\
\hline 3 & BCC-CSM1.1 & $360 \times 232$ & 2.82 & $\checkmark$ & \\
\hline 4 & CanESM2 & $256 \times 192$ & 3.70 & $\checkmark$ & $\checkmark$ \\
\hline 5 & CCSM4 & $320 \times 384$ & 2.94 & $\checkmark$ & $\checkmark$ \\
\hline 6 & CESM1-BGC & $320 \times 384$ & & $\checkmark$ & \\
\hline 7 & CESM1-CAM5 & $320 \times 384$ & 4.0 & $\checkmark$ & \\
\hline 8 & CMCC-CESM & $182 \times 149$ & & $\checkmark$ & \\
\hline 9 & CMCC-CMS & $182 \times 149$ & & $\checkmark$ & \\
\hline 10 & CNRM-CM5 & $362 \times 292$ & 3.25 & $\checkmark$ & \\
\hline 11 & CSIRO-Mk3.6.0 & $192 \times 189$ & 4.09 & $\checkmark$ & $\checkmark$ \\
\hline 12 & FGOALS-g2 & $360 \times 196$ & 3.37 & $\checkmark$ & $\checkmark$ \\
\hline 13 & FIO-ESM & $320 \times 384$ & & $\checkmark$ & \\
\hline 14 & GFDL CM3 & $360 \times 200$ & 3.96 & $\checkmark$ & \\
\hline 15 & GFDL-ESM2G & $360 \times 210$ & 2.43 & $\checkmark$ & \\
\hline 16 & GFDL-ESM2M & $360 \times 200$ & 2.44 & $\checkmark$ & \\
\hline 17 & HadGEM2-CC & $360 \times 216$ & & $\checkmark$ & \\
\hline 18 & HadGEM2-ES & $360 \times 216$ & 4.60 & $\checkmark$ & \\
\hline 19 & INM-CM4 & $360 \times 340$ & 2.08 & $\checkmark$ & $\checkmark$ \\
\hline 20 & IPSL-CM5A-LR & $182 \times 149$ & 4.13 & $\checkmark$ & \\
\hline 21 & IPSL-CM5A-MR & $182 \times 149$ & 4.11 & $\checkmark$ & \\
\hline 22 & IPSL-CM5B-LR & $182 \times 149$ & 2.61 & $\checkmark$ & \\
\hline 23 & MIROC5 & $256 \times 224$ & 2.72 & $\checkmark$ & $\checkmark$ \\
\hline 24 & MIROC-ESM & $256 \times 192$ & 4.65 & $\checkmark$ & \\
\hline 25 & MIROC-ESM-CHEM & $256 \times 192$ & & $\checkmark$ & \\
\hline 26 & MPI-ESM-LR & $256 \times 220$ & 3.63 & $\checkmark$ & $\checkmark$ \\
\hline 27 & MPI-ESM-MR & $802 \times 404$ & 3.45 & $\checkmark$ & $\checkmark$ \\
\hline 28 & MRI-CGCM3 & $360 \times 368$ & 2.61 & $\checkmark$ & $\checkmark$ \\
\hline 29 & NorESM1-M & $320 \times 384$ & 2.80 & $\checkmark$ & $\checkmark$ \\
\hline 30 & NorESM1-ME & $320 \times 384$ & & $\checkmark$ & $\checkmark$ \\
\hline 31 & BCC-CSM1.1-m & $360 \times 232$ & 2.89 & & \\
\hline 32 & CESM1-WACCM & $320 \times 384$ & & & \\
\hline 33 & $\mathrm{CMCC}-\mathrm{CM}$ & $182 \times 149$ & & & \\
\hline 34 & CNRM-CM5.2 & $362 \times 292$ & & & \\
\hline 35 & EC-EARTH & $362 \times 292$ & & & \\
\hline 36 & MPI-ESM-P & $256 \times 220$ & 3.46 & & \\
\hline 37 & MRI-ESM1 & $360 \times 368$ & & & $\checkmark$ \\
\hline
\end{tabular}

scenarios used for the CMIP5 future projections. However, climate projections from the SSP and RCP scenarios that follow a similar global forcing pathway should be comparable but not identical. In this study, we examine regional DSL projections under low-, medium-, and high-emission pathways using three RCP scenarios (RCP2.6, RCP4.5, and RCP8.5) and three SSP scenarios (SSP1-2.6, SSP2-4.5, and SSP5-8.5), with nominal forcing levels in each set of scenarios reaching approximately $2.6,4.5$, and $8.5 \mathrm{~W} \mathrm{~m}^{-2}$ in 2100 , respectively (O'Neill et al. 2016). The projected changes for both CMIP5 and CMIP6 are calculated as differences between averages over 1995-2014 (i.e., the last two decades of the CMIP6 historical simulations) and the last two decades of the twenty-first century (2081-2100).

Coupled climate models often contain spurious longterm changes (i.e., drift) that are unrelated to either the internal climate variability or changes in external forcing. Hobbs et al. (2016) demonstrated that model responses to external forcing are not sensitive to the magnitude of model drift, indicating that model outputs can be corrected by de-drifting without biasing the results. The model drift at each grid point is estimated by fitting a quadratic polynomial to the full time series of the preindustrial simulation (Sen Gupta et al. 2013). Based on the branch time information provided in the file metadata, we identify the correct segment of the preindustrial simulation that parallels to the historical simulation and future projections, which are then dedrifted by subtracting the estimated drift from the corresponding preindustrial simulation. We also calculate the magnitude of the Atlantic meridional overturning circulation (AMOC) as the maximum ocean overturing streamfunction in the North Atlantic north 


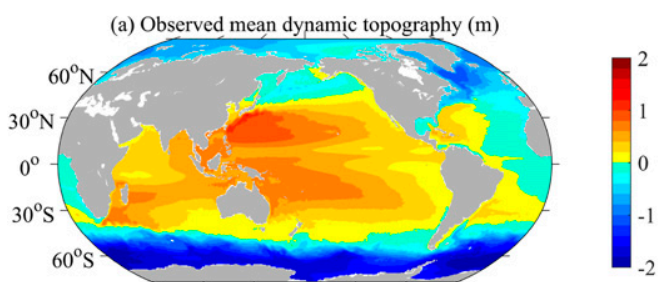

(b) CMIP6 MMM minus obs

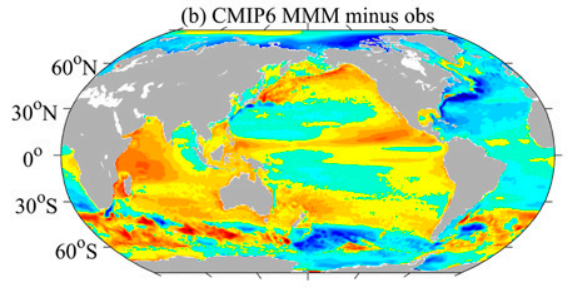

(c) CMIP5 MMM minus obs

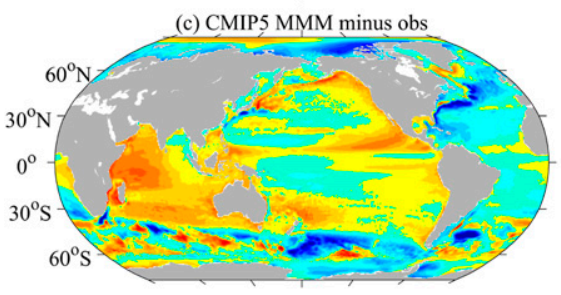

(d) CMIP6 minus CMIP5

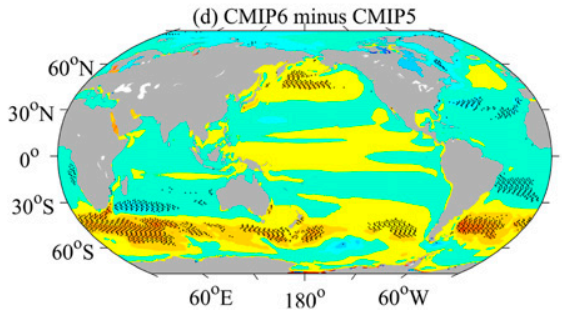

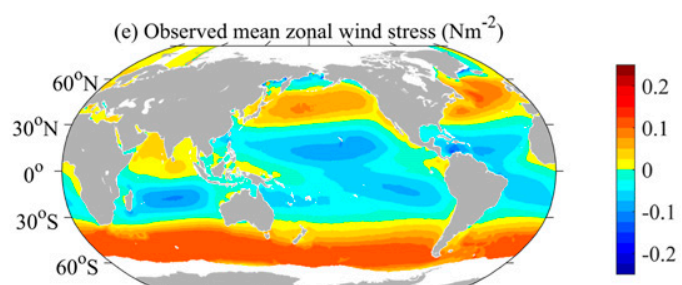
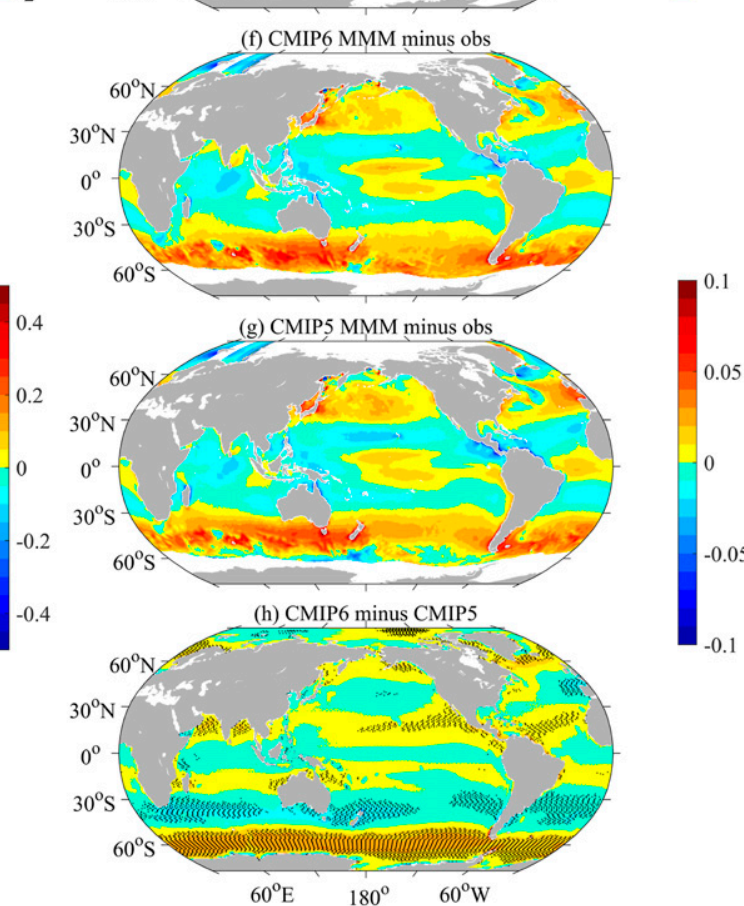

FIG. 1. (a) Observed mean ocean dynamic topography over 1992-2012; differences of the (b) CMIP6 and (c) CMIP5 multimodel-averaged mean sea level over 1986-2005 from the observed mean dynamic topography; and (d) differences between the mean sea level from CMIP6 and CMIP5. (e)-(h) As in (a)-(d), but for mean sea surface zonal wind stress from QuikSCAT observations (1999-2009) and climate model simulations (1986-2005). Stippling in lower panels indicates where the difference between CMIP6 and CMIP5 is statistically significant at the $95 \%$ confidence level based on the two-sample $t$ test.

of $30^{\circ} \mathrm{N}$ with the upper $500 \mathrm{~m}$ excluded (Gregory et al. 2005).

\section{Mean-state biases}

The mean sea level is closely related to the upperocean general circulation through geostrophic balance, with relatively high (low) sea level within the subtropical (subpolar) gyres (Fig. 1a). The surface zonal wind stress is dominated by the easterly trade winds over the subtropical and tropical oceans and the westerly winds over the middle latitudes (Fig. 1e). We use the Taylor diagram to evaluate model performance in simulating global patterns of the mean sea level and surface zonal wind stress with reference to their corresponding observations (Fig. 2). The CMIP5 and CMIP6 models can simulate the mean sea level reasonably well, with global spatial correlations between the simulations and observations generally above 0.95 (Fig. 2a). In terms of both the multimodel mean (MMM) and the intermodel spread on the Taylor diagram, there is no clear difference between CMIP5 and CMIP6 and both ensembles have a similarly good simulation of the mean sea level. In contrast, the surface zonal wind stress is slightly better simulated in the CMIP6 ensemble compared to the CMIP5 ensemble (Fig. 2b). In particular, there are fewer models (nine vs five) from CMIP5 to CMIP6 having pattern correlations with the observations lower than 0.95. However, the spatial standard deviation of mean surface zonal wind stress remains larger in most of the CMIP5 and CMIP6 models than in QuikSCAT observations.

Despite the overall good model performances in simulating the mean sea level and surface zonal wind 

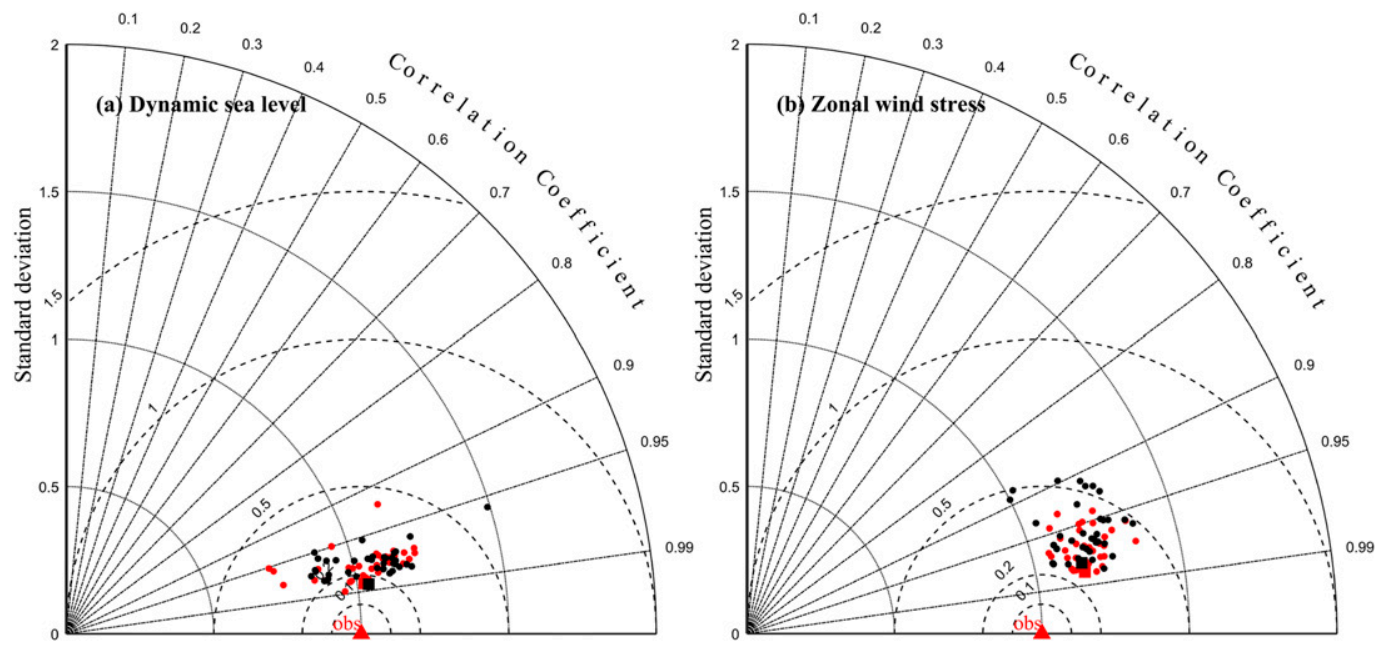

FIG. 2. Taylor diagrams of the simulated mean (a) sea level and (b) sea surface zonal wind stress from 37 CMIP5 models (black) and 39 CMIP6 models (red) compared against the corresponding observations (red triangle) globally. Dots indicate individual models and squares indicate multimodel averages. The radius is for the spatial standard deviation normalized by the reference observations and the angular coordinate for the pattern correlation.

The arcs represent root-mean-square differences (RMSD) relative to the reference.

stress, there still exist significant regional biases in model simulations. The CMIP5 and CMIP6 multimodel ensemble averages share very similar bias patterns relative to the observations (Fig. 1). We first look at model biases in the equatorial region. The mean sea level and zonal wind stress averaged over the equatorial band $\left(2^{\circ} \mathrm{S}-2^{\circ} \mathrm{N}\right)$ illustrate differences between the observations and model simulations in individual ocean basins (Fig. 3). The mean sea level in both CMIP5 and CMIP6 is biased high in the western and eastern tropical Pacific but biased low in the central tropical Pacific $\left(\sim 140^{\circ} \mathrm{E}-150^{\circ} \mathrm{W}\right)$ relative to the observations (Figs. 1b,c). These biases lead to a larger (smaller) sea level gradient between the western (eastern) boundary and the central tropical Pacific than the observed gradient (Fig. 3a). The tropical Pacific mean sea level biases are consistent with the easterly (westerly) wind stress biases immediately west (east) of the date line (Figs. 1f,g); that is, the simulated easterly trade winds are too strong over the western tropical Pacific but are too weak over the central tropical Pacific compared to the QuikSCAT observations (Fig. 3b). In the Indian Ocean and to a lesser extent in the Atlantic Ocean, the simulated zonal slope of mean sea level along the equator is weaker than the observed slope (Fig. 3a), as a result of the too weak zonal wind stress in model simulations (Fig. 3b). In short, the biases in mean sea level and surface zonal wind stress are largely consistent in the equatorial region with no significant change from CMIP5 to CMIP6 (Figs. 1d,h). Note that the QuikSCAT observations are only available over 1999-2009 during which period the tropical
Pacific experienced anomalously strong trade winds (England et al. 2014), which might affect model biases estimated above. Indeed, smaller biases can be found in the central tropical Pacific when defining the observed climatology of surface zonal wind stress using ERA5 over a longer period, 1986-2005 or 1979-2018, although the bias patterns remain similar (Fig. 3b). Over the subtropical bands $\left(15^{\circ}-30^{\circ} \mathrm{N} / \mathrm{S}\right)$, both CMIP5 and CMIP6 show easterly wind stress biases, that is, too strong easterly wind stress except over the northern Indian Ocean where the annual mean wind stress is westerly rather than
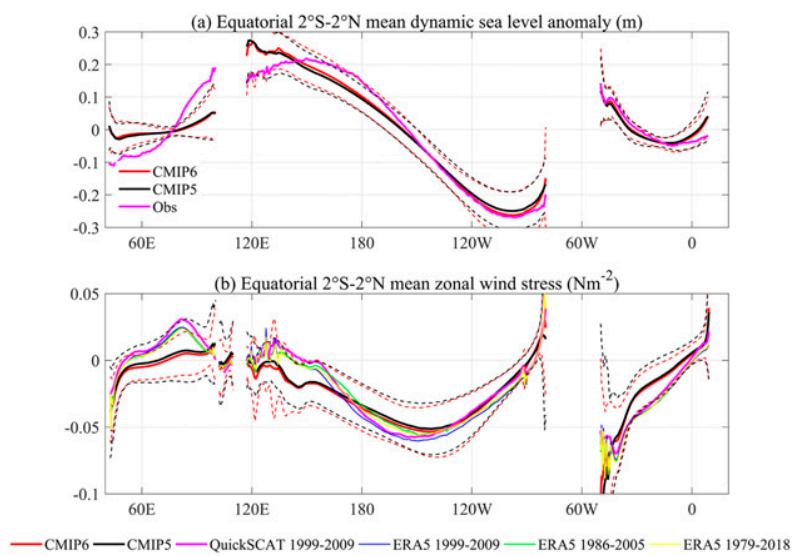

FIG. 3. Averaged (a) mean sea level deviations relative to zonal averages over each ocean basin and (b) mean sea surface zonal wind stress in the equatorial region $\left(2^{\circ} \mathrm{S}-2^{\circ} \mathrm{N}\right)$. Solid red and black lines are for the multimodel averages and the dashed lines mark the uncertainty ranges as twice the intermodel standard deviations. 


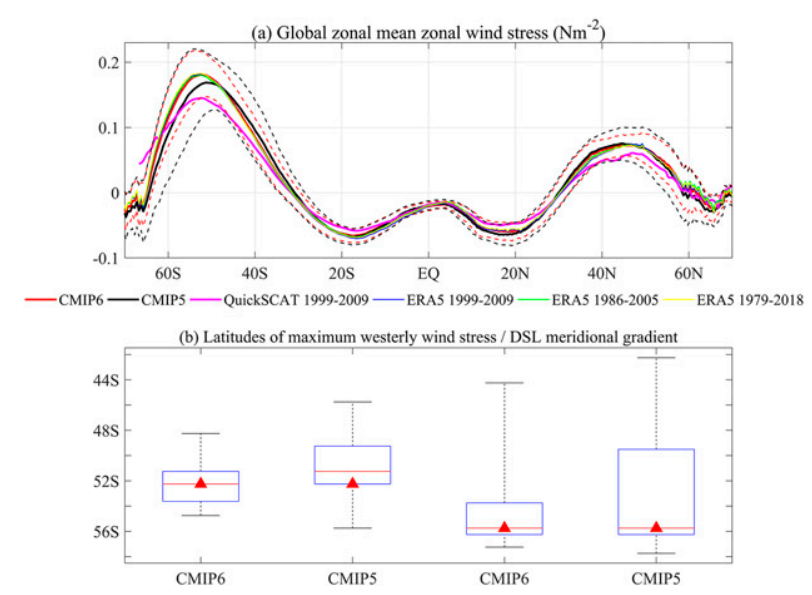

FIG. 4. (a) Global zonally averaged sea surface zonal wind stress. Solid lines are for the multimodel averages and the dashed lines mark the uncertainty ranges as twice the intermodel standard deviations. (b) Latitudes of the maximum westerly sea surface wind stress (left two boxes) and latitudes of the maximum meridional gradient of the mean sea level (right two boxes) in the Southern Ocean. Box edges indicate the 25th and 75th percentiles in each CMIP ensemble with the median shown as red. Red triangles indicate the observed latitudes from the QuikSCAT observations or the mean ocean dynamic topography (Maximenko et al. 2009).

easterly (Figs. 1f,g). These subtropical zonal wind stress biases have been reduced from CMIP5 to CMIP6, with significant reductions over the Northern Hemisphere roughly between $15^{\circ}$ and $30^{\circ} \mathrm{N}$ (Fig. $1 \mathrm{~h}$ ).

Over the midlatitudes, both CMIP5 and CMIP6 simulate too strong westerly wind stress compared to the QuikSCAT observations (Fig. 4a). ERA5 exhibits stronger midlatitude westerly wind stress than the QuikSCAT observations, partly because scatterometers measure wind stress relative to the ocean surface velocity but the reanalysis products do not fully consider the effects of surface ocean currents (Chelton and Freilich 2005; Belmonte Rivas and Stoffelen 2019). Despite the overestimated midlatitude westerly wind stress, mean sea level biases in the western boundary current regions of the North Pacific and North Atlantic indicate weaker mean sea level meridional gradients in model simulations, indicating that the simulated Kuroshio Extension and Gulf Stream might be weaker than the observed. In contrast, positive mean sea level biases in the Southern Hemisphere midlatitude band (Figs. 1b,c) imply stronger subtropical ocean gyres, which is dynamically consistent with the simulated overly strong westerly wind stress compared to the QuikSCAT observations (Fig. 4a). The CMIP6 models exhibit significantly stronger (weaker) surface westerly wind stress over the high (middle) latitudes of the Southern Hemisphere than the CMIP5 models (Fig. 1h), implying a more poleward location of the simulated Southern Hemisphere westerly wind stress. Indeed, the CMIP6 models show an improvement in comparison to the CMIP5 models in terms of the latitudinal position of the maximum westerly wind stress in the Southern Hemisphere (Fig. 4a). In contrast to the CMIP5 MMM in which the global zonal mean maximum westerly wind stress lies equatorward $\left(50^{\circ} \mathrm{S}\right)$ of that in the ERA5 and QuikSCAT observations $\left(52^{\circ} \mathrm{S}\right)$, the CMIP6 MMM westerly wind stress peaks at a latitude nearly the same as the observations (Fig. 4a). While approximately $75 \%$ of the CMIP5 models have an equatorward bias in their locations of the maximum westerly wind stress, roughly half of the CMIP6 models show an equatorward bias and the other half show a poleward bias with the CMIP6 median latitude close to the observed latitude (Fig. 4b). The reasons for the reduction in the equatorward bias in the Southern Hemisphere westerly wind stress should be explored but it is beyond the scope of this study.

It is of interest to see whether the reduced equatorward bias in the Southern Hemisphere westerly wind stress has any effect on the simulated mean sea level. The poleward displacement of the surface westerly wind stress from CMIP5 to CMIP6 is expected to force a similar poleward displacement of the subtropical gyres (Lyu et al. 2020), indicated by significantly higher mean sea level at the Southern Hemisphere middle latitudes in CMIP6 than in CMIP5 (Fig. 1d). To evaluate this displacement, we identify the latitude of the maximum meridional gradients of the global zonal mean sea level (Landerer et al. 2014), that is, the location of the strongest zonal velocity (Fig. 4b). The multimodel median latitude in both CMIP5 and CMIP6 ensembles is close to the observed latitude of the maximum sea level meridional gradient near $56^{\circ} \mathrm{S}$. However, the considerable intermodel spread in CMIP5, with some individual models having severe equatorward bias, has been reduced in CMIP6. It would appear that the simulated mean sea level in the Southern Ocean have benefited from the improved representation of the location of the Southern Hemisphere westerly wind stress, although other factors like the buoyancy forcing and model eddy parameterizations may also have impacts in individual models (Kuhlbrodt et al. 2012; Meijers et al. 2012).

Refining horizonal resolution of the ocean model might not necessarily lead to a reduction in mean sea level bias in the coupled climate model simulations, as the origin of bias might be dominated by atmospheric or air-sea coupling processes (Morim et al. 2020). For example, the latitude of the maximum mean sea level meridional gradient in the Southern Ocean is close to the observed latitude at $56^{\circ} \mathrm{S}$ in CNRMCM6.1 but exhibits a large equatorward bias at $47^{\circ} \mathrm{S}$ in 

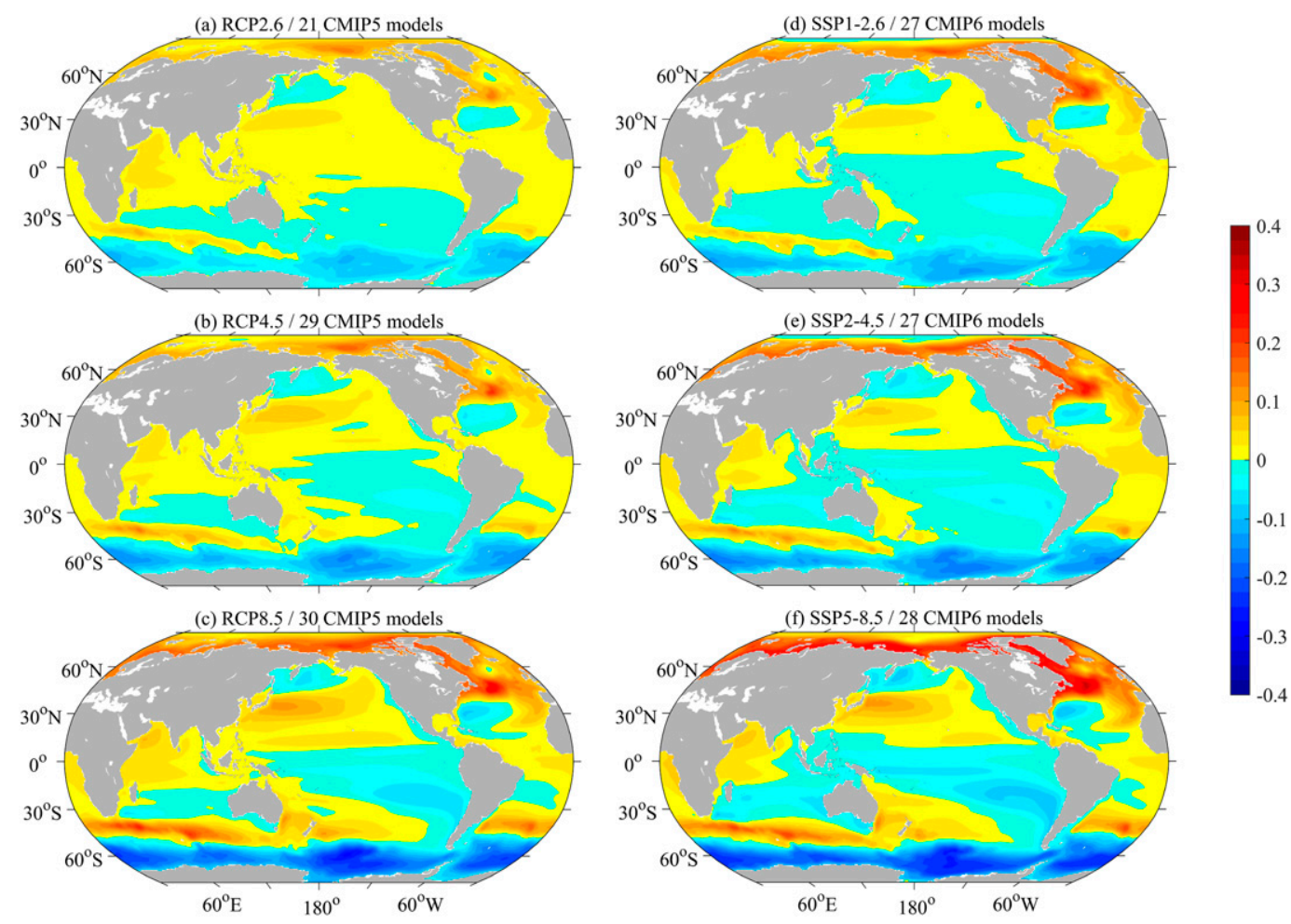

FIG. 5. Multimodel mean DSL projections (m) from the (a)-(c) CMIP5 and (d)-(f) CMIP6 ensembles under (top) low-emission scenarios (RCP2.6 and SSP1-2.6), (middle) medium-emission scenarios (RCP4.5 and SSP2-4.5), and (bottom) high-emission scenarios (RCP8.5 and SSP5-8.5).

CNRM-CM6.1-HR, which might be partly due to a more equatorward location of the westerly wind stress simulated in CNRM-CM6.1-HR (48 S) than in CNRM-CM6.1 (505).

\section{Future projections}

In this section, we examine and compare regional DSL projections by the end of the twenty-first century available from up to 28 CMIP6 models (Table 1) and up to 30 CMIP5 models (Table 2). The spatial patterns of the MMM DSL projections are very similar in CMIP5 and CMIP6 for each of the different scenarios (Fig. 5). Several outstanding regional features are shared by the CMIP5 and CMIP6 MMM projections including large DSL rise in the Arctic, a dipole-like structure in the North Atlantic with large DSL rise north of the Gulf Stream and relatively weak DSL fall to the south, another similar but sign-reversed dipole structure in the North Pacific, and the circumpolar belt-like DSL changes in the Southern Ocean with rising (falling) DSL at middle (high) latitudes.

Notably larger magnitudes of DSL projections can be found particularly in the North Atlantic and Arctic from CMIP5 to CMIP6 (Figs. 5 and 6). Grose et al. (2020) also reported that the CMIP6 project larger DSL changes around Australia compared to the CMIP5 (Fig. 5). Under high-emission scenarios, the projected DSL rise in MMM is enhanced by up to $10 \mathrm{~cm}$ off the northeast coast of North America and along the Arctic coast (Figs. 5c,f). A larger weakening of the AMOC is also projected from CMIP5 to CMIP6 (Fig. 7a). Four CMIP6 models (CESM2, CESM2-WACCM, MRI-ESM2.0, and NorESM2-LM) project a large AMOC weakening of $\sim 15 \mathrm{~Sv}\left(1 \mathrm{~Sv}=10^{6} \mathrm{~m}^{3} \mathrm{~s}^{-1}\right)$ by the end of the twentyfirst century that exceeds the upper range of the CMIP5 projections. The projected magnitudes of the AMOC weakening among models are well correlated with the projected DSL changes in the northwest Atlantic subpolar region (Fig. 7b) and the Arctic coastal region south of $80^{\circ} \mathrm{N}$ (Fig. 7c). This is consistent with Yin et al. (2010) showing that a water-hosing experiment with a freshwater flux added into the North Atlantic simulates a weakening of the AMOC accompanied by rapid DSL rise not only off the northeast coast of North America but also along the Arctic coast. Possible mechanisms linking the AMOC change to the Arctic DSL change include the following: 1) the AMOC change could affect the local surface fluxes (e.g., wind, precipitation, river runoff) in the Arctic region via atmospheric teleconnections; 
(a) DSL projection: global zonal average

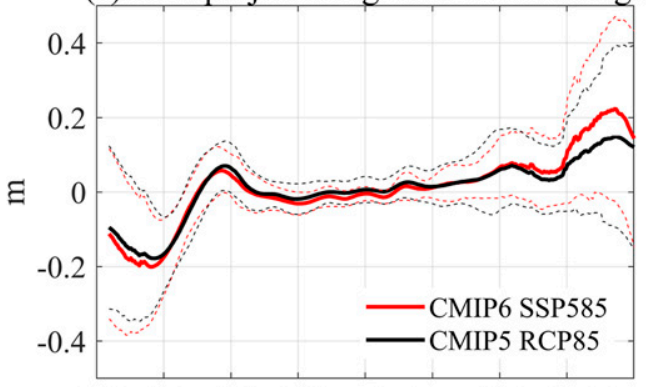

80S $60 \mathrm{~S} 40 \mathrm{~S} 20 \mathrm{~S}$ EQ $20 \mathrm{~N} 40 \mathrm{~N} 60 \mathrm{~N} 80 \mathrm{~N}$

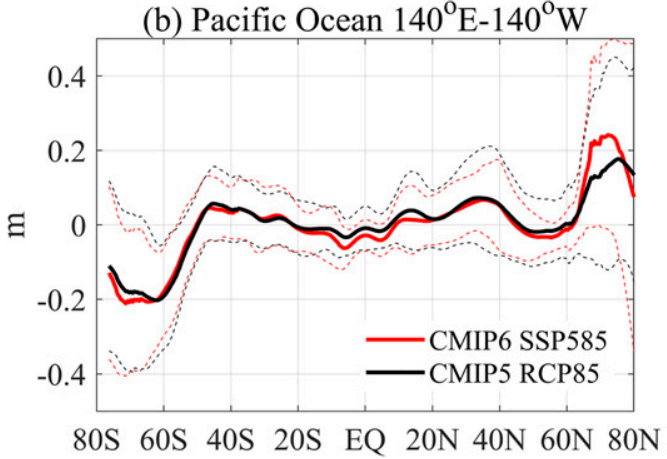

(c) Indian Ocean $30^{\circ} \mathrm{E}-90^{\circ} \mathrm{E}$

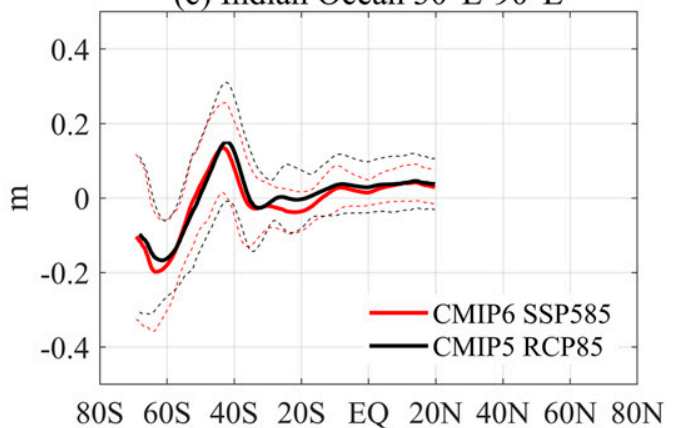

(d) Atlantic Ocean $80^{\circ} \mathrm{W}-0^{\circ} \mathrm{W}$

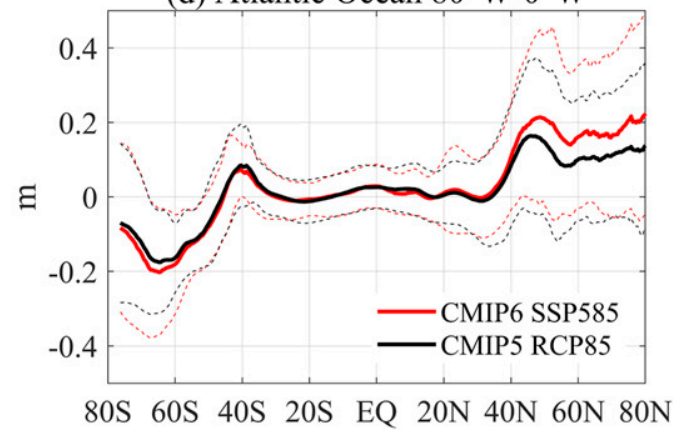

FIG. 6. Zonally averaged DSL projections (m) from the CMIP5 (black lines) and CMIP6 (red lines) model ensembles under high-emission scenarios (RCP8.5 and SSP5-8.5). Solid lines are for the multimodel averages and the dashed lines mark the uncertainty ranges as twice the intermodel standard deviations.

2) the North Atlantic surface heat uptake under anthropogenic warming drives both the AMOC weakening and warmer ocean temperature (Gregory et al. 2016), with the latter implying increased ocean heat transport from the Atlantic to the Arctic, which could further enhance sea ice loss and freshwater input (Årthun et al. 2019); and 3) the DSL rise signal along the east coast of the North Atlantic (Fig. 5) could propagate along the coast into the Arctic in the form of the arrested topographic wave (Csanady 1978; Hughes et al. 2019).

The regions with relatively large DSL projections also exhibit considerable intermodel spread (Fig. 8). The ensemble spread generally increases from low-emission scenarios to high-emission scenarios with similar patterns. There is a large reduction $(5.7$ to $2.1 \mathrm{~cm}$ under medium-emission scenarios) in the global mean ensemble standard deviation of regional DSL projections from CMIP3 to CMIP5 (Church et al. 2013). In contrast, there is no significant change from CMIP5 to CMIP6, although locally the ensemble spread could increase (e.g., subtropical North Atlantic) or reduce (e.g., northwest Pacific) slightly.

Compared to the CMIP5 models, some of the CMIP6 models have a larger equilibrium climate sensitivity
(ECS), defined as the equilibrium global mean surface temperature increase with a doubling of $\mathrm{CO}_{2}$ (Gregory et al. 2004). The ECS range has significantly increased from $2.1^{\circ}-4.7^{\circ} \mathrm{C}$ in CMIP5 to $1.8^{\circ}-5.6^{\circ} \mathrm{C}$ in CMIP6. Ten of the CMIP6 models have their ECS values exceeding the upper limit of the CMIP5 range, leading to an increase (statistically insignificant) of the MMM ECS from $3.3^{\circ}$ to $3.9^{\circ} \mathrm{C}$ (Zelinka et al. 2020). This ECS increase is mainly due to stronger positive cloud feedbacks (Zelinka et al. 2020). A larger climate sensitivity implies not only a larger global mean surface warming but also larger surface warming in most regions (Grose et al. 2018). The increased magnitudes of MMM DSL projections from CMIP5 to CMIP6 (Figs. 5 and 6) could be due to the inclusion of those CMIP6 models with relatively high ECS and an increase of the MMM ECS.

Here, we present a preliminary assessment of the implications of a larger climate sensitivity for regional DSL changes, focusing on DSL projections from four modeling groups that found a significantly larger ECS with their latest CMIP6 models compared with their CMIP5 models (Fig. 9). For these models, a larger ECS from CMIP5 to CMIP6 is usually accompanied by a larger DSL rise in the northwest Atlantic and along the 

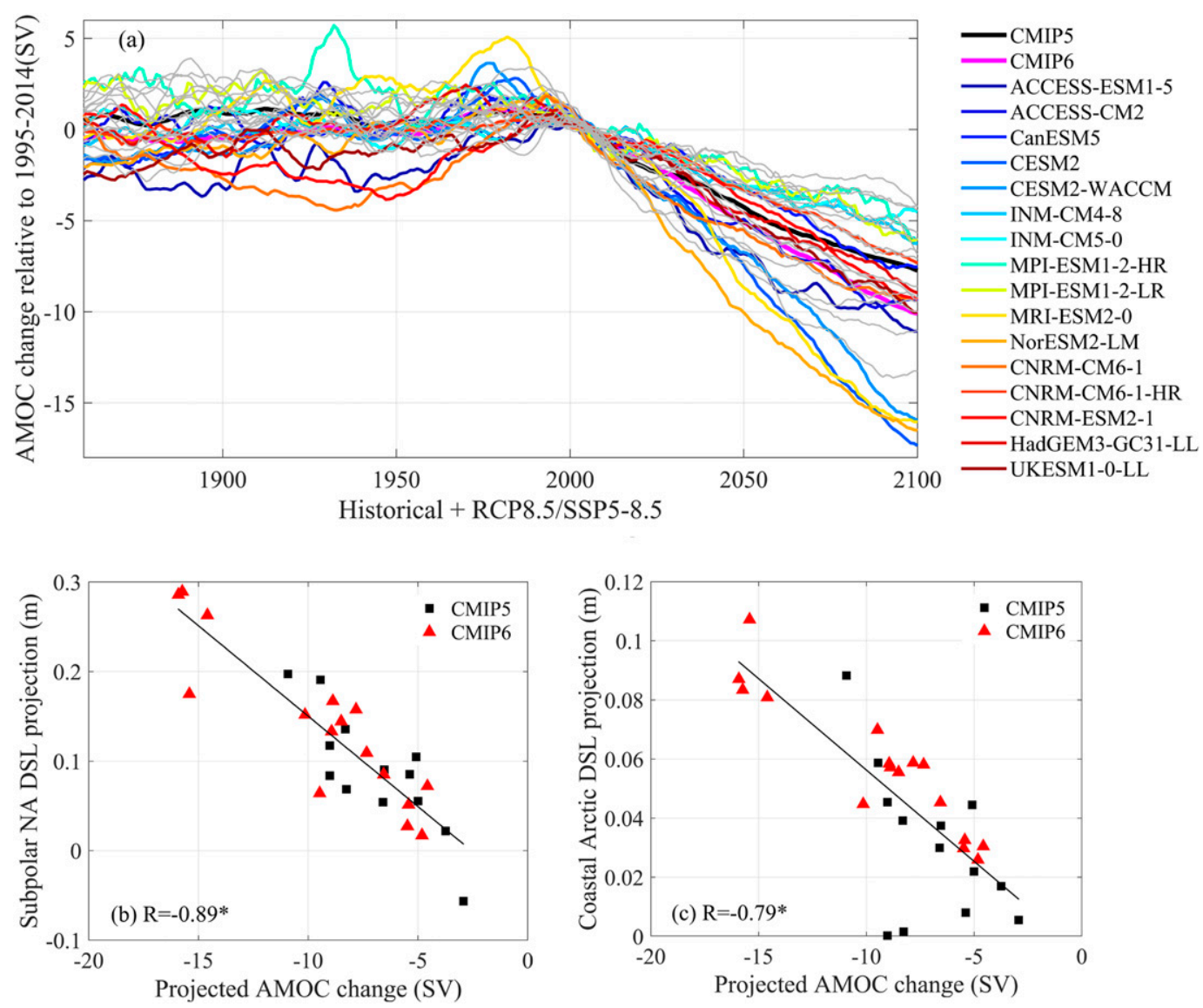

FIG. 7. (a) The 11-yr smoothed annual time series of the AMOC magnitudes relative to the average of 1995-2014 from historical simulations and future projections under high-emission scenarios (RCP8.5 and SSP5-8.5). Gray lines are for the CMIP5 models and colored lines are for the CMIP6 models and multimodel averages. Also shown are scatterplots for the projected AMOC changes vs the projected DSL changes (b) in the northwest Atlantic subpolar region averaged over $45^{\circ}-60^{\circ} \mathrm{N}, 70^{\circ}-30^{\circ} \mathrm{W}$ and (c) in the Arctic coastal region averaged between $70^{\circ}$ and $80^{\circ} \mathrm{N}$. The projected changes are calculated as differences between 1995-2014 and 2081-2100 under high-emission scenarios. Black (red) symbols indicate CMIP5 (CMIP6) models. The black lines are linear fits. The correlations with an asterisk $(*)$ are significant at the $95 \%$ confidence level.

Arctic coast. Models with a large ECS such as the CESM2 (Fig. 9g) have contributed to the increase of the upper range and MMM of the projected AMOC weakening and DSL rise in these two regions from CMIP5 to CMIP6 (Fig. 7). However, an increase of the ECS does not imply that the regional DSL projections increase uniformly, with different model versions from the same group having complicated differences in regional DSL projections (Fig. 9). For example, in contrast to the other models, the projected DSL changes in the northwest Atlantic weaken from ACCESS1.3 of CMIP5 to ACCESS-CM2 of CMIP6, although the ECS increases from $3.55^{\circ}$ to $4.7^{\circ} \mathrm{C}$ (Figs. 9a,e). Of course, in addition to the ECS change, there are many other factors related to the model physics that could influence regional DSL projections, such as the use of different eddy parameterization and mixing schemes, model spinup to a different mean climate state, or even using a different ocean model, which is the case for CanESM2 and CanESM5 (Swart et al. 2019).

\section{Linkages between mean-state simulations and future projections}

In this section, we look for relationships between model mean-state simulations and future projections across models. Given that the CMIP5 and CMIP6 share very similar mean-state biases (Fig. 1) and DSL projections (Fig. 5), we combine the available 30 CMIP5 models and 28 CMIP6 models that provide DSL projections to form a large ensemble for our intermodel analysis. Considering that different regions have different 


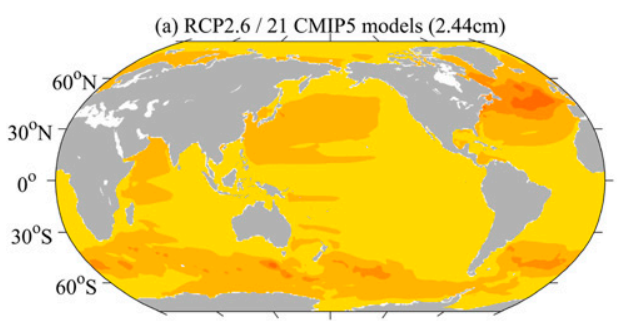

(b) RCP4.5 / 29 CMIP5 models $(2.71 \mathrm{~cm})$

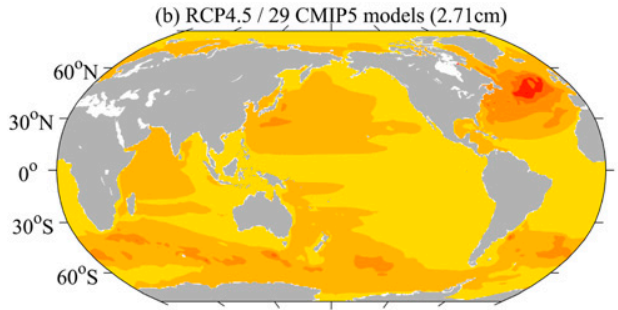

(c) RCP8.5 / 30 CMIP5 models $(3.79 \mathrm{~cm})$

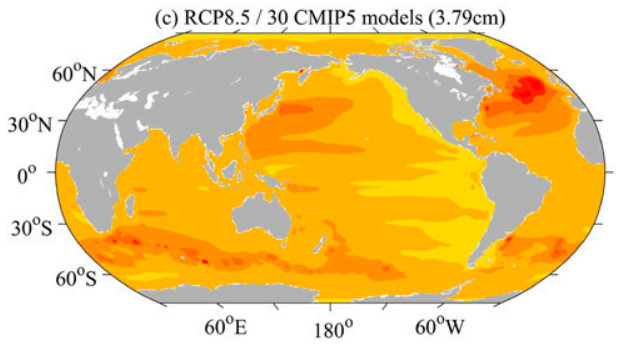

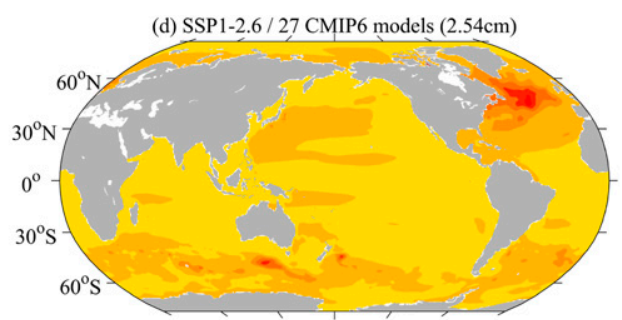

(e) SSP2-4.5 / 27 CMIP6 models $(2.75 \mathrm{~cm})$

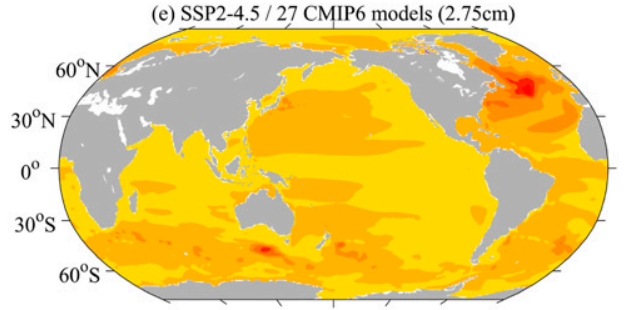

(f) SSP5-8.5 / 28 CMIP6 models $(3.57 \mathrm{~cm})$

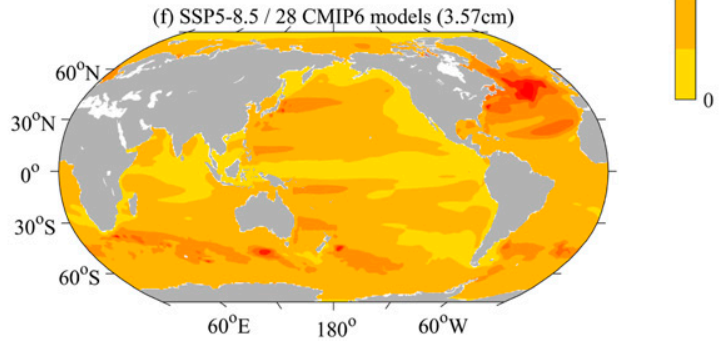

FIG. 8. Multimodel ensemble standard deviations (m) of DSL projections from the (a)-(c) CMIP5 and (d)-(f) CMIP6 ensembles under (top) low-emission scenarios (RCP2.6 and SSP1-2.6), (middle) medium-emission scenarios (RCP4.5 and SSP2-4.5), and (bottom) high-emission scenarios (RCP8.5 and SSP5-8.5). The global weighted-mean value of ensemble standard deviations is given in each panel.

types of model mean-state biases which might originate from different processes, we carry out our analysis in four representative regions separately: the tropical Pacific, the Southern Ocean, the North Pacific, and the North Atlantic.

In each region, we first define an index to represent the spread of model mean-state simulations as well as differences between the observations and model simulations. We then conduct a composite analysis to examine differences in both the mean states and future projections between models with significant contrasts in their simulated mean climate states. Specifically, models from the combined CMIP5 and CMIP6 ensemble with the defined mean-state index at least 0.5 standard deviation below or above the MMM are selected for composite analysis. The composite differences between these two subsets of models are rescaled to represent magnitudes corresponding to one standard deviation of the defined mean-state index.

\section{a. Tropical Pacific}

We first look at the tropical Pacific, as the rapid sea level rise in the western tropical Pacific observed by the satellite altimeter since 1993 has attracted much attention. Although these short-term trends are largely due to the Pacific interdecadal climate variability (e.g., Zhang and Church 2012; Lyu et al. 2017), it is of great interest whether the forced signal from the anthropogenic forcing is already detectable in the altimeter record (Hamlington et al. 2014; Palanisamy et al. 2015; Fasullo and Nerem 2018). However, the long-standing model biases in the tropical Pacific could limit the model skills in projecting future climate changes. Here, we consider a common model bias in the tropical Pacific (i.e., the cold-tongue bias), which means the simulated equatorial Pacific cold tongue extends farther west than observed. A cold-tongue bias index is defined as the averaged SST under current climatology in the central equatorial Pacific $\left(2^{\circ} \mathrm{S}-2^{\circ} \mathrm{N}, 160^{\circ} \mathrm{E}-140^{\circ} \mathrm{W}\right.$; see the black box in Fig. 10b, roughly the center of cold SST biases relative to the observations). Most of the models (52 out of 58) exhibit the cold-tongue bias, with the central equatorial Pacific region SST colder than the observed (Fig. 10a).

Compared to the MMM, a larger cold-tongue bias (i.e., a colder climatological SST centered in the central 
(a) ACCESS1-3 (ECS=3.55)

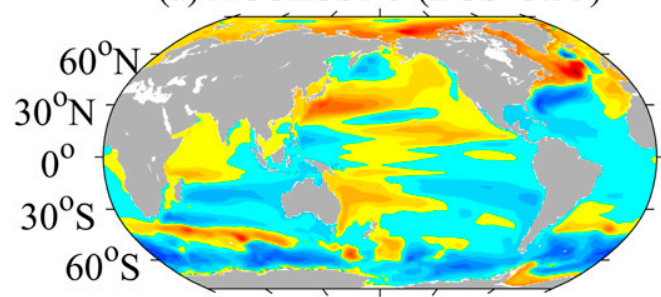

(b) CanESM2 (ECS=3.7)

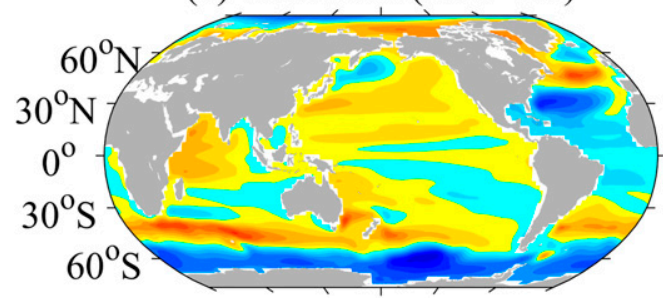

(c) CESM1-CAM5 (ECS=4)

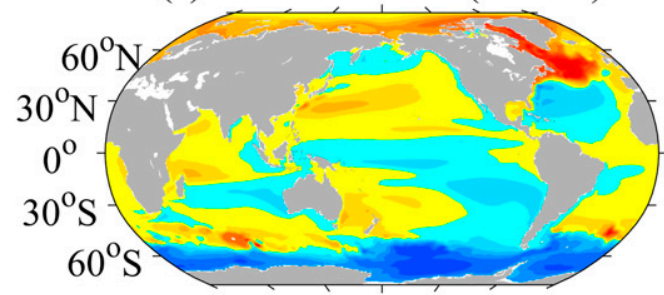

(d) CNRM-CM5 (ECS $=3.25)$

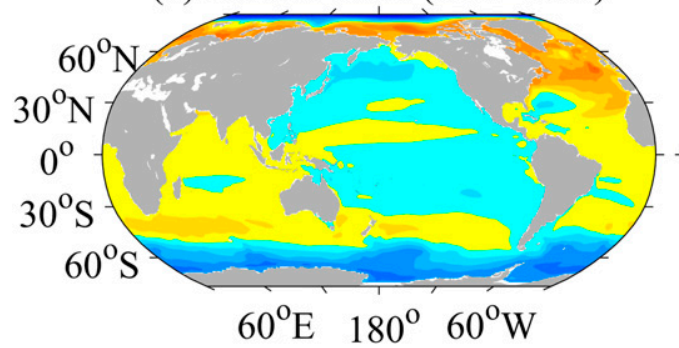

(e) ACCESS-CM2 (ECS=4.7)

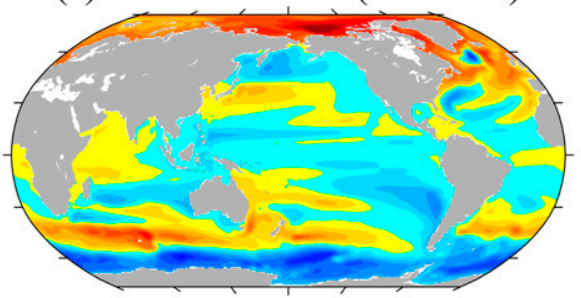

(f) CanESM5 (ECS=5.64)

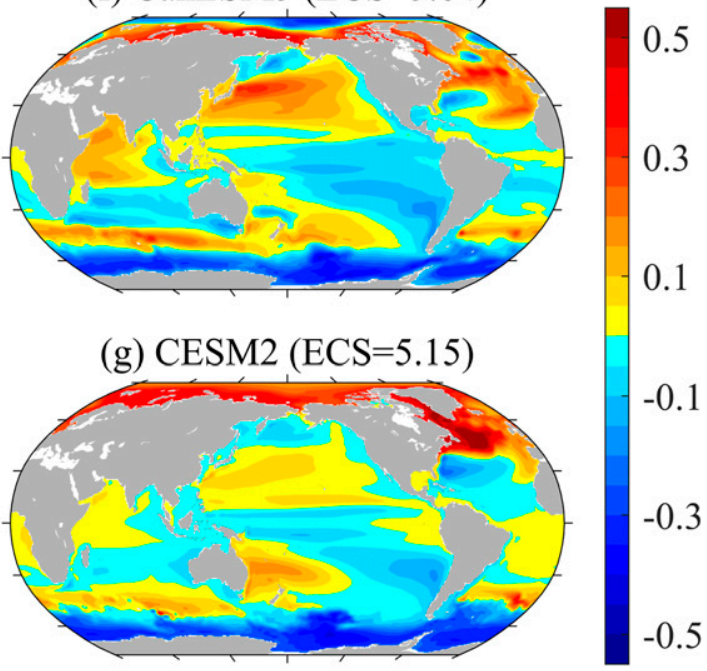

(h) CNRM-CM6-1 (ECS=4.9)

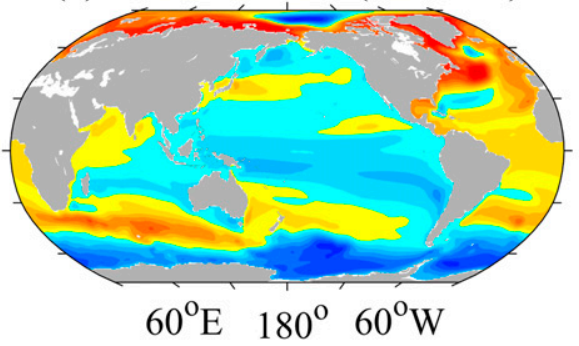

FIG. 9. Regional DSL projections (m) under high-emission scenarios from four modeling groups: (a)-(d) CMIP5 RCP8.5 and (e)-(h) CMIP6 SSP5-8.5. The equilibrium climate sensitivity (ECS; ${ }^{\circ} \mathrm{C}$ ) for each model is given after the model name in the subtitles.

equatorial Pacific) reflects an excessive westward extension of the cold tongue (Fig. 10b). A larger coldtongue bias is also accompanied by stronger (weaker) climatological trade winds in the western (eastern) equatorial Pacific (Fig. 10c), which further drive lower (higher) mean sea level in the central (western and eastern) equatorial Pacific (Fig. 10d). In terms of future projections, models with a larger cold-tongue bias tend to project an anomalous warming center in the coldtongue bias region, which means the projected El Niñolike SST warming in the MMM extend farther west (Fig. 10e). Our analysis is consistent with other studies using different methodologies but showing very similar effects of the cold-tongue bias on the tropical Pacific warming pattern (Huang and Ying 2015; Li et al. 2016). Accordingly, these models with a larger cold-tongue bias also tend to project a larger weakening of the trade winds (Fig. 10f) and thus a DSL fall in the western tropical Pacific centered near $10^{\circ} \mathrm{N}$ and $10^{\circ} \mathrm{S}$ (Fig. 10g). Given that most models exhibit a cold-tongue bias, we should expect a slightly larger DSL rise $(1-2 \mathrm{~cm})$ in the western tropical Pacific than the MMM projections if the consequences of the cold-tongue bias are corrected based on this intermodel relationship (Fig. 10). However, it 


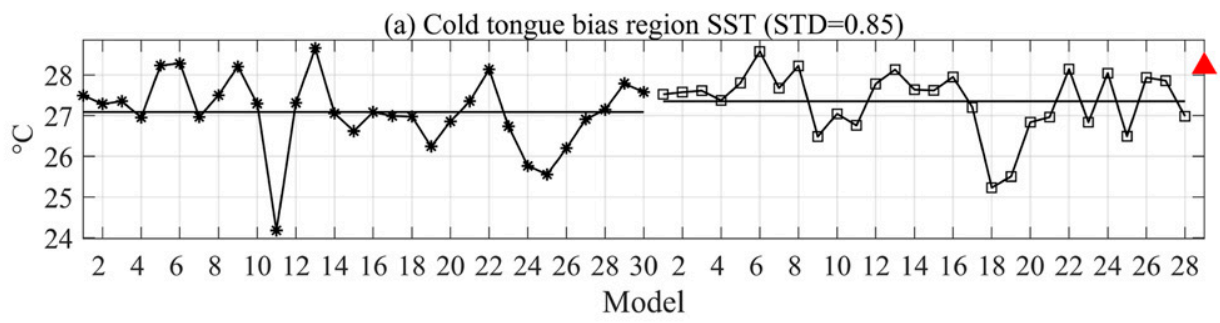

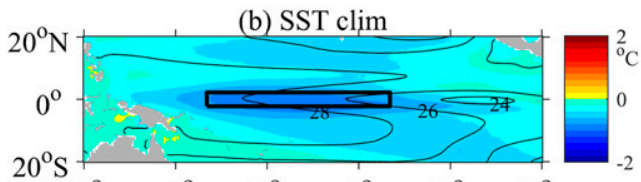

$120^{\circ} \mathrm{E} 150^{\circ} \mathrm{E} 180^{\circ} \mathrm{W} 150^{\circ} \mathrm{W} 120^{\circ} \mathrm{W} \quad 90^{\circ} \mathrm{W}$
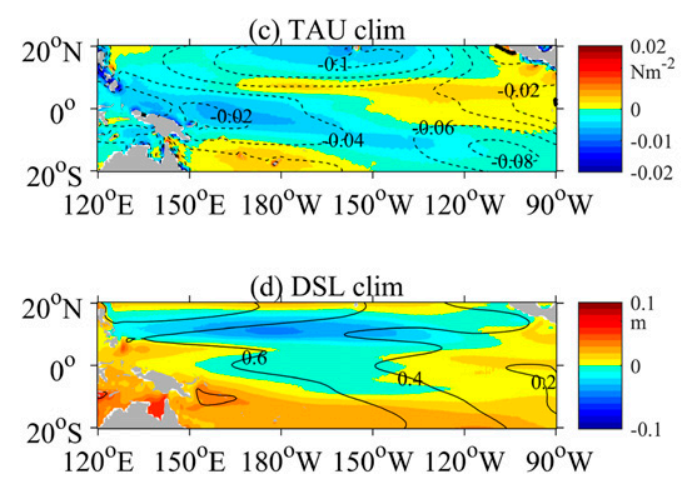

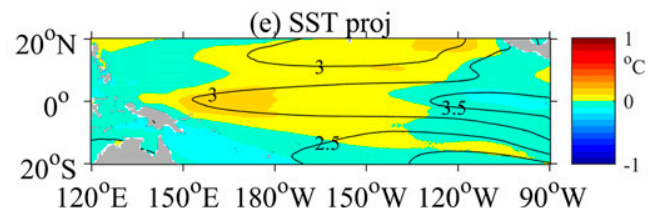

$120^{\circ} \mathrm{E} 150^{\circ} \mathrm{E} 180^{\circ} \mathrm{W} 150^{\circ} \mathrm{W} 120^{\circ} \mathrm{W} 90^{\circ} \mathrm{W}$

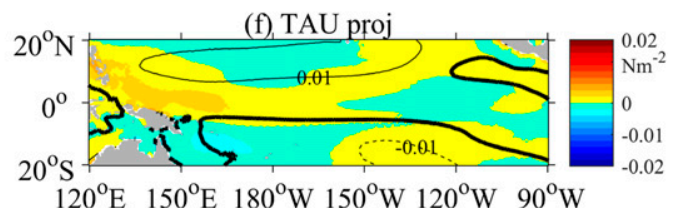

$120^{\circ} \mathrm{E} 150^{\circ} \mathrm{E} 180^{\circ} \mathrm{W} 150^{\circ} \mathrm{W} 120^{\circ} \mathrm{W} \quad 90^{\circ} \mathrm{W}$

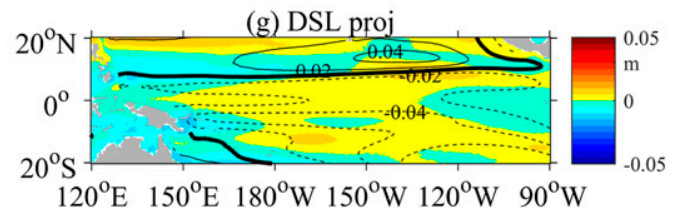

FIG. 10. (a) Cold-tongue bias index defined as the climatological SST averaged in the central equatorial Pacific $\left[2^{\circ} \mathrm{S}-2^{\circ} \mathrm{N}, 160^{\circ} \mathrm{E}-140^{\circ} \mathrm{W}\right.$; see black box in (b)] from 30 CMIP5 models (asterisks) and 28 CMIP6 models (squares). The horizontal lines denote the averages of each ensemble and the red triangle marks the observed value. Models with a cold-tongue bias index at least 0.5 standard deviation below or above the CMIP5 and CMIP6 multimodel mean are selected for composite analysis. Also shown are composite differences of the SST (b) climatology and (e) projection, the surface zonal wind stress (c) climatology and (f) projection, the DSL (d) climatology and (g) projection corresponding to a stronger cold-tongue bias of $0.85^{\circ} \mathrm{C}$. The multimodel averaged climatology and projection patterns are superimposed as contours.

should be kept in mind that the projected DSL changes in the tropical Pacific and the uncertainties related to the cold-tongue bias have much weaker magnitudes compared to the internal variability of DSL. Therefore, it is very challenging to distinguish the forced DSL changes due to the anthropogenic forcing from the internal variability (e.g., Lyu et al. 2014; Carson et al. 2015; Lyu et al. 2015).

\section{b. Southern Ocean}

The Southern Ocean is a hotspot region for DSL projections (Fig. 5). Here, we examine how the latitudinal position of the climatological westerly wind stress affects DSL projections in the Southern Ocean. Although the equatorward bias of the westerly wind stress has been reduced from CMIP5 to CMIP6 (Fig. 4a), there still exists a large intermodel spread in the simulated positions of the westerly wind stress among models (Figs. 4b and 11a). For those models with the simulated climatological westerly wind stress located at a more equatorward location (Fig. 11b), the climatological fields of wind stress curl (Fig. 11c) and mean sea level (Fig. 11d) are also displaced equatorward. Accordingly, the boundary between the subtropical ocean gyres and the ACC simulated in these models should be also located further equatorward (Lyu et al. 2020). In future projections, the westerly wind stress is projected to intensify and shift poleward (Fig. 11e). Consistent with previous studies (Kidston and Gerber 2010; Bracegirdle et al. 2013), models with the climatological westerly wind stress located farther equatorward tend to project a larger poleward shift of the westerly wind stress (Fig. 11e). Mechanisms related to the atmospheric dynamics such as the eddy-mean flow feedback (Barnes et al. 2010; Barnes and Hartmann 2010) have been proposed to explain the dependence of future shift in the westerly winds on the climatological location of the westerly winds as found in the Southern Ocean. 

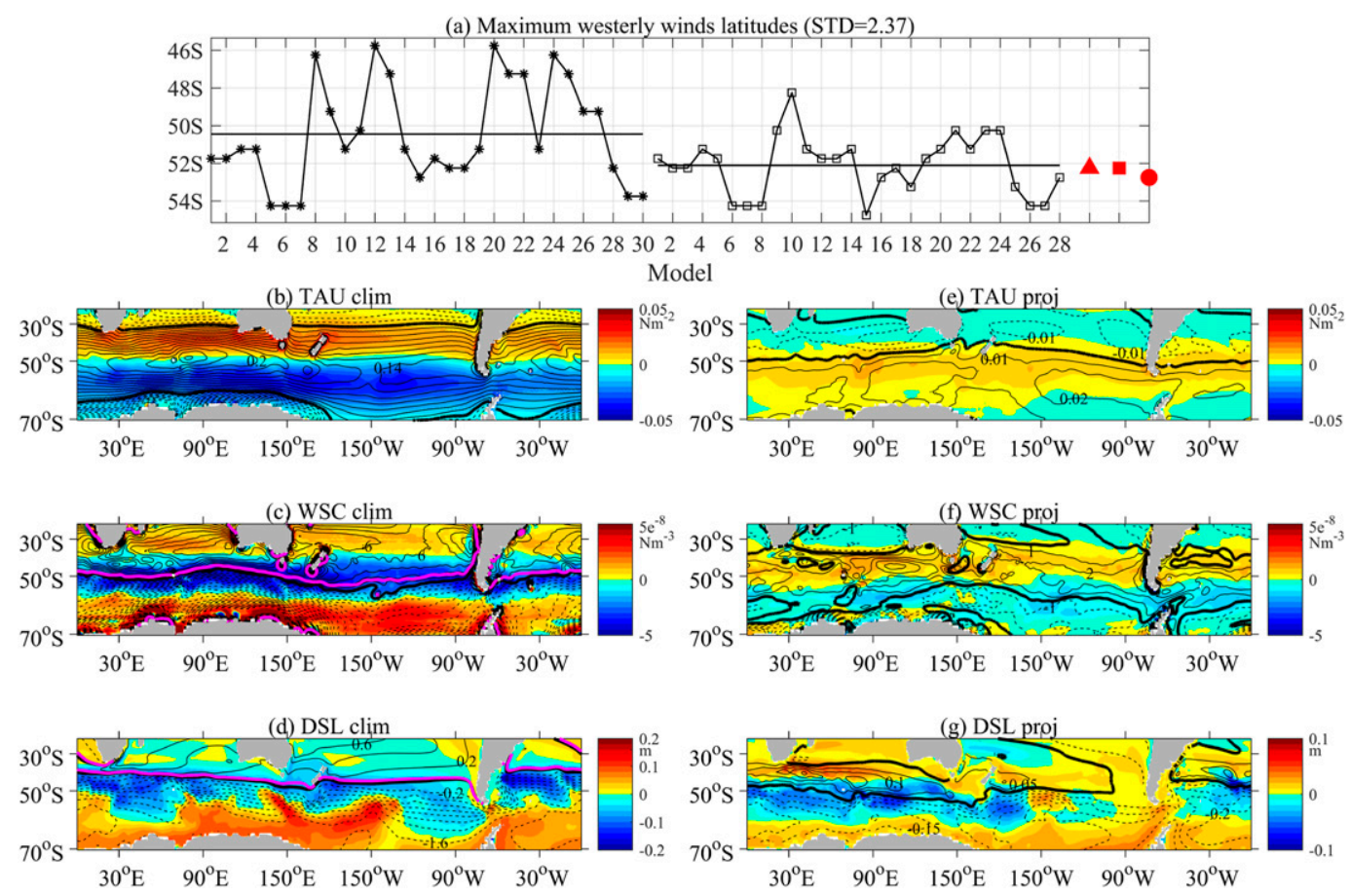

FIG. 11. (a) Latitudes of the maximum climatological surface westerly wind stress over the Southern Ocean from 30 CMIP5 models (asterisks), 28 CMIP6 models (squares), QuikSCAT observations over 1999-2009 (red triangle), ERA5 over 1999-2009 (red square), and ERA5 over 1986-2005 (red circle). The horizontal lines denote the averages of each model ensemble. Models with the latitude of the westerly wind stress at least 0.5 standard deviation below or above the CMIP5 and CMIP6 multimodel mean are selected for composite analysis. Also shown are composite differences of the surface zonal wind stress (b) climatology and (e) projection, the wind stress curl (c) climatology and (f) projection, and the DSL (d) climatology and (g) projection corresponding to a more equatorwardlocated westerly wind stress of $2.37^{\circ}$. The multimodel averaged climatology and projection patterns are superimposed as contours. To show an equatorward displacement in the subgroup of models with the simulated westerly wind stress located more equatorward relative to the multimodel mean, the bold pink lines in (c) and (d) mark the zero contours of the mean wind stress curl and mean sea level when the multimodel mean and composite differences are added together.

The wind stress change is the dominant cause of ocean circulation and sea level change in the Southern Ocean (Bouttes et al. 2012). A larger poleward shift of the westerly wind stress is accompanied with stronger wind stress curl changes relative to the MMM projections (Fig. 11f), which further drive generally larger magnitudes of DSL changes including both the midlatitude DSL rise and the high-latitude DSL fall (Fig. 11g). Based on the above relationships, the DSL projections in the Southern Ocean might be overestimated in the CMIP5 MMM and those individual models with the simulated climatological westerly wind stress biased equatorward compared to the observations (Fig. 11a). For example, an equatorward bias of $2.37^{\circ}$ in the Southern Ocean westerly wind stress location (i.e., one intermodel standard deviation) corresponds to a larger DSL rise by $2-5 \mathrm{~cm}$ in the Southern Indian Ocean near $40^{\circ} \mathrm{S}$ in the future projection (Fig. $11 \mathrm{~g}$ ). The projected
DSL changes in these models having a more equatorward location of the climatological westerly wind stress are also displaced equatorward relative to the MMM DSL projections (Fig. 11g). In short, the varying latitudes of the climatological westerly wind stress among models induce uncertainties in both the locations and magnitudes of the projected DSL changes in the Southern Ocean.

\section{c. North Pacific}

The latitudinal position of the climatological westerly wind stress has similar effects on DSL projections in the North Pacific (Fig. 12) as in the Southern Ocean (Fig. 11). A more equatorward location of the simulated climatological westerly wind stress (Fig. 12b) is accompanied by an equatorward displacement of the climatological wind stress curl (Fig. 12c) and mean sea level (Fig. 12d) in the North Pacific. As in the Southern 
(a) Maximum westerly winds latitudes $(\mathrm{STD}=2.10)$

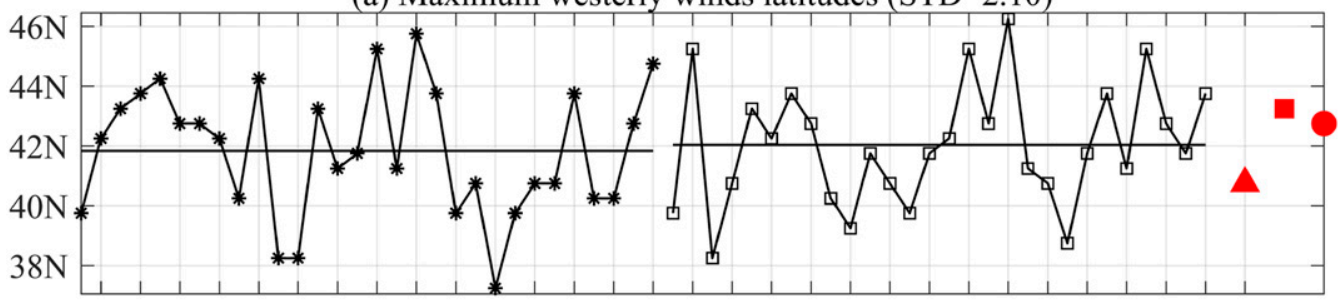

$246681012141618202224262830244 \quad 6 \quad 810121416182022242628$

Model

(b) TAU clim

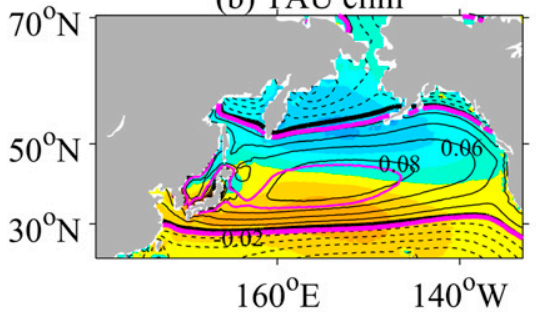

(c) WSC clim

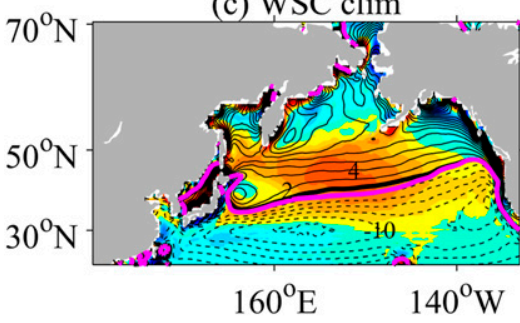

(d) DSL clim

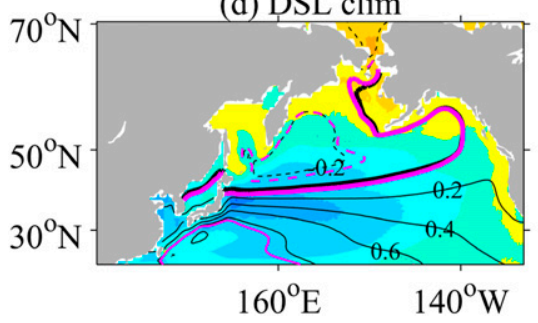

(e) TAU proj

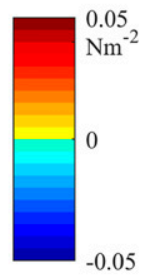

$30^{\circ} \mathrm{N}$

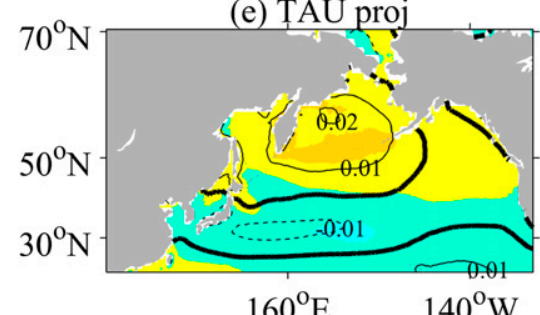

(f) WSC proj

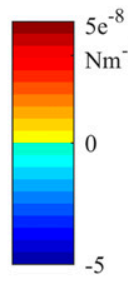

$70^{\circ} \mathrm{N}$
$50^{\circ} \mathrm{N}$
$30^{\circ} \mathrm{N}$

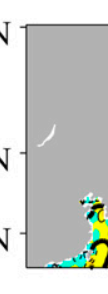

$160^{\circ} \mathrm{E} \quad 140^{\circ} \mathrm{W}$

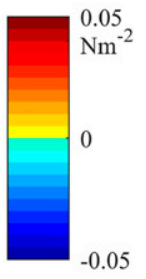

$-0.05$
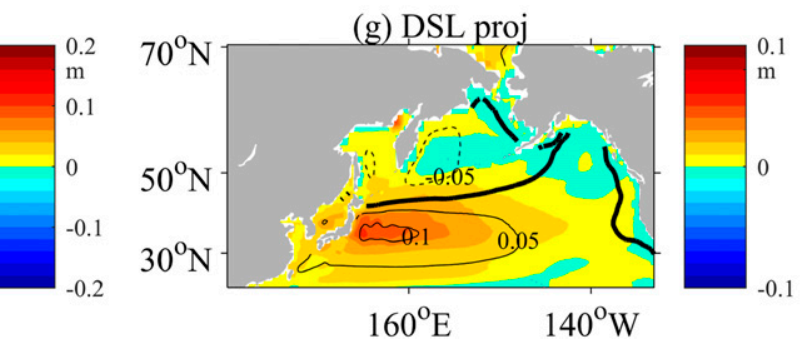

FIG. 12. (a) Latitudes of the maximum climatological surface westerly wind stress over the North Pacific $\left(160^{\circ} \mathrm{E}-\right.$ $160^{\circ} \mathrm{W}$ ) from 30 CMIP5 models (asterisks), 28 CMIP6 models (squares), QuikSCAT observations over 1999-2009 (red triangle), ERA5 over 1999-2009 (red square), and ERA5 over 1986-2005 (red circle). The horizontal lines denote the averages of each model ensemble. Models with the latitude of the westerly wind stress at least 0.5 standard deviation below or above the CMIP5 and CMIP6 multimodel mean are selected for composite analysis. Also shown are composite differences of the surface zonal wind stress (b) climatology and (e) projection, the wind stress curl (c) climatology and (f) projection, and the DSL (d) climatology and (g) projection corresponding to a more equatorward-located westerly wind stress of $2.10^{\circ}$. The multimodel averaged climatology and projection patterns are superimposed as contours. To show an equatorward displacement in the subgroup of models with the simulated westerly wind stress located more equatorward relative to the multimodel mean, the pink lines in (b)-(d) indicate selective contours of the corresponding fields when the multimodel mean and composite differences are added together.

Ocean, the westerly wind stress with a more equatorward location in the North Pacific also tends to have a larger poleward shift in future projections (Fig. 12e) and thus has larger magnitudes of wind stress curl changes
(Fig. 12f) relative to the MMM projections. The larger wind stress curl changes in turn drive larger DSL changes in the North Pacific including a larger DSL rise (fall) within the subtropical (subpolar) gyre (Fig. 12g), 
indicating a wind-driven intensification of both gyres at the surface (Suzuki et al. 2005).

Therefore, models with their simulated climatological westerly wind stress over the North Pacific located more equatorward tend to project larger DSL changes in the North Pacific. For example, a more equatorward location of $2.1^{\circ}$ (i.e., one intermodel standard deviation) corresponds to a larger DSL rise by up to $5 \mathrm{~cm}$ to the southeast of Japan in the future projection (Fig. 12g). The DSL projections in the North Pacific might be overestimated (underestimated) in models with the simulated North Pacific climatological westerly wind stress located more equatorward (poleward) than the observed. However, due to the uncertainty in the observed latitude of the North Pacific climatological westerly wind stress $\left(41^{\circ} \mathrm{N}\right.$ in QuikSCAT observations and $43^{\circ} \mathrm{N}$ in ERA5 compared to $42^{\circ} \mathrm{N}$ in CMIP5 and CMIP6 MMM; Fig. 12a), the potential bias in the North Pacific MMM DSL projections cannot be determined from this intermodel relationship.

\section{d. North Atlantic}

In the North Atlantic, models with a more equatorward location of the climatological westerly wind stress (Fig. 13b) also exhibit an equatorward displacement of their simulated climatological wind stress curl (Fig. 13c) and a weaker mean sea level field (Fig. 13d) compared to the MMM. The westerly wind stress over the North Atlantic is also projected to shift poleward in the future (Barnes and Polvani 2013). However, those models in which the simulated North Atlantic climatological westerly wind stress is located more equatorward do not project a larger poleward shift of the westerly wind stress relative to the MMM as in the Southern Ocean (Fig. 11e) and North Pacific (Fig. 12e). Instead, the future projections of the North Atlantic westerly wind stress in these models show an equatorward displacement relative to the MMM projections, in accordance with their more equatorward located climatological westerly wind stress (Fig. 13e).

Correspondingly, the projected wind stress curl changes in these models are generally weaker than the MMM projections (Fig. 13f) rather than stronger as in the Southern Ocean (Fig. 11f) and North Pacific (Fig. 12f). The projected dipole-like DSL changes in these models are also weaker than the MMM projections (Fig. 13g). Note that although the weaker DSL projections are consistent with the weaker wind stress curl projections, the accompanying changes in surface buoyancy fluxes (not shown) might play more important roles in driving DSL changes in the North Atlantic (e.g., Bouttes et al. 2014; Gregory et al. 2016). In short, models with the simulated North Atlantic climatological westerly wind stress located more equatorward tend to project weaker DSL changes in the North Atlantic. For example, a more equatorward location in the North Atlantic climatological westerly wind stress of $2.98^{\circ}$ (i.e., one intermodel standard deviation) implies smaller DSL rise by up to $15 \mathrm{~cm}$ centered around $50^{\circ} \mathrm{N}, 35^{\circ} \mathrm{W}$ in the future projection (Fig. 13g).

Consistent with the above composite analysis (Figs. 13d,g), further intermodel correlations also indicate that models with a more equatorward location of the North Atlantic climatological westerly wind stress indeed tend to simulate higher mean sea level in the northwest Atlantic subpolar region (Fig. 14a) and project smaller DSL rise there (Fig. 14b). These models also tend to project a smaller weakening of the AMOC although the intermodel relationship is statistically insignificant (Fig. 14c). A larger DSL rise along the Arctic coast is also projected in these models (not shown), given that the magnitudes of projected AMOC change and coastal Arctic DSL change are well correlated across models (Fig. 7c). The CMIP6 MMM has a more poleward location $\left(52^{\circ} \mathrm{N}\right)$ of the North Atlantic climatological westerly wind stress than the observations $\left(50^{\circ} \mathrm{N}\right)$. Such a poleward bias exists in most (19 out of 28 ) of the CMIP6 models (Fig. 13a). Therefore, the intermodel relationship identified here implies that the CMIP6 MMM projections might overestimate the AMOC weakening and the rapid DSL rise in the North Atlantic and coastal Arctic.

Gregory et al. (2005) found that models with a stronger AMOC in their control climate tend to have a larger weakening of the AMOC under $\mathrm{CO}_{2}$ increase. Inspired by this earlier finding, here we also examine how the simulated AMOC magnitude under current climatology influences future projections. Models that simulate a stronger AMOC in their current climatology, which is accompanied by lower mean sea level in the northwest Atlantic subpolar region (Fig. 14d), tend to project larger DSL rise in the northwest Atlantic subpolar region (Fig. 14e) and a larger weakening of the AMOC (Fig. 14f). The close relationship between projected AMOC change and coastal Arctic DSL change (Fig. 7c) also implies a larger coastal Arctic DSL rise in these models (not shown). A composite analysis based on the combined CMIP5 and CMIP6 ensemble indeed shows lower mean sea level (Fig. 14g) and larger DSL projections (Fig. 14h) particularly in the northwest Atlantic subpolar region in models with a stronger AMOC in their current climatology (Fig. 14i).

Note that the simulated latitudes of the North Atlantic climatological westerly wind stress and the simulated AMOC magnitudes under current climatology are barely correlated $(R=0.14)$ with each other 
(a) Maximum westerly winds latitudes ( $\mathrm{STD}=2.98)$

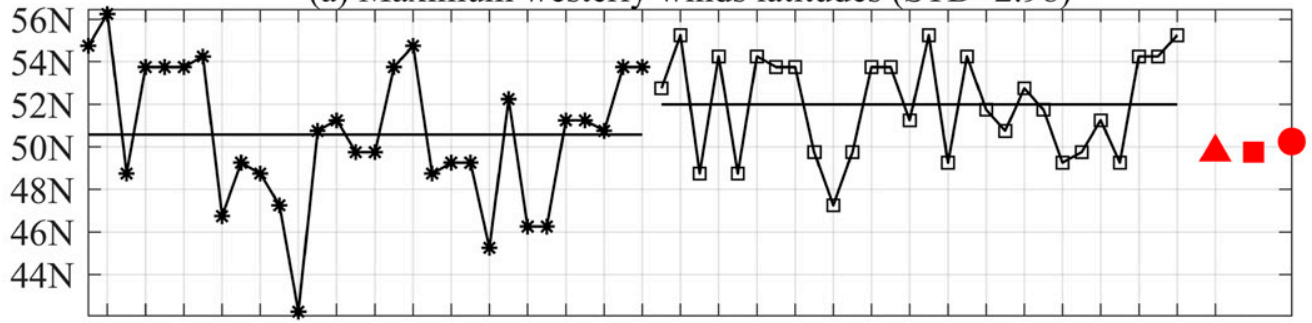

$24681012141618202224262830246 \quad 810121416182022242628$

Model

(b) TAU clim

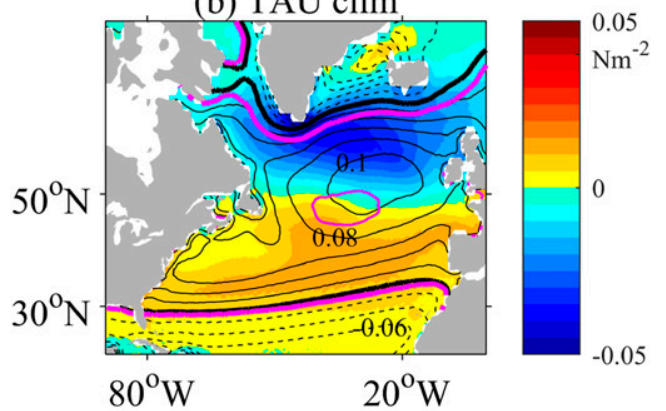

(c) WSC clim

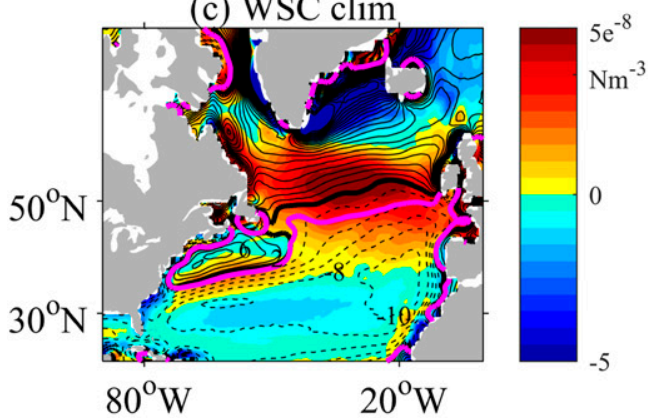

(d) DSL clim

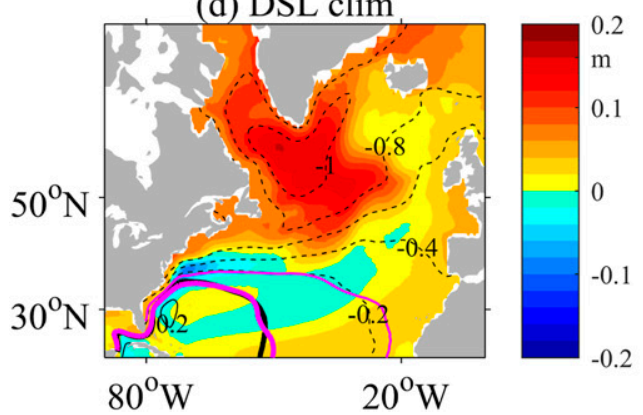

(e) TAU proj

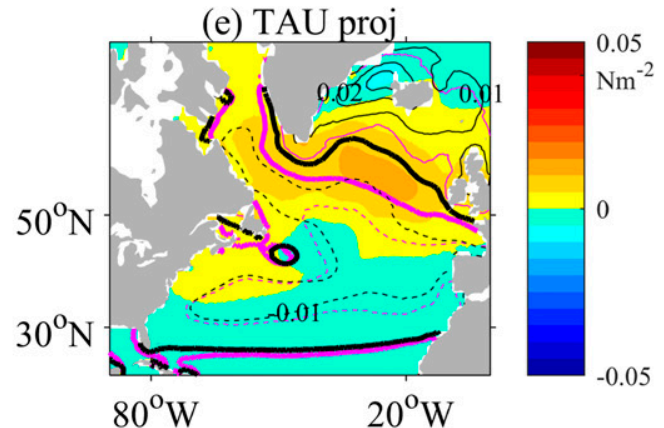

(f) WSC proj

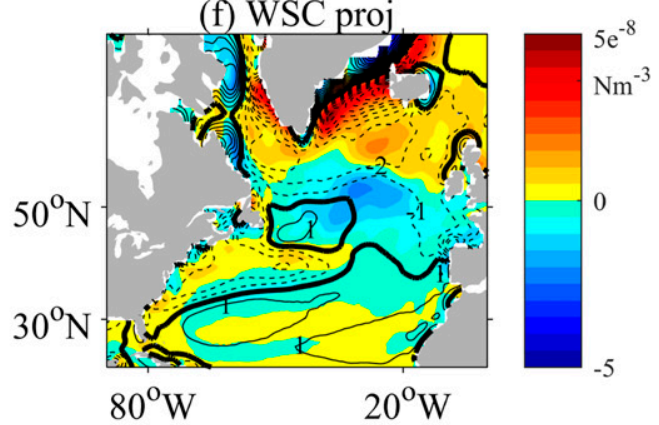

(g) DSL proj

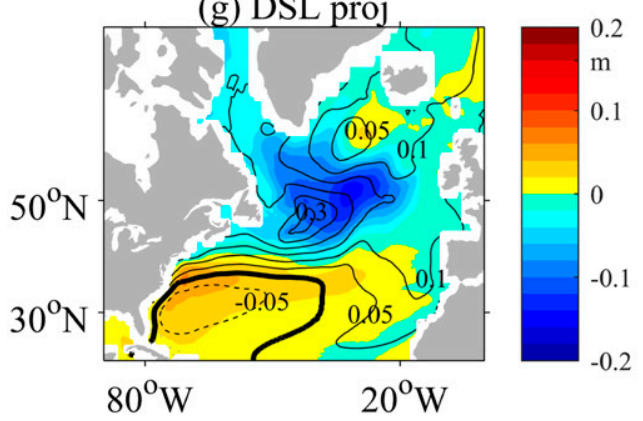

FIG. 13. (a) Latitudes of the maximum climatological surface westerly wind stress over the North Atlantic $\left(50^{\circ}-\right.$ $10^{\circ} \mathrm{W}$ ) from 30 CMIP5 models (asterisks), 28 CMIP6 models (squares), QuikSCAT observations over 1999-2009 (red triangle), ERA5 over 1999-2009 (red square), and ERA5 over 1986-2005 (red circle). The horizontal lines denote the averages of each model ensemble. Models with the latitude of the westerly wind stress at least 0.5 standard deviation below or above the CMIP5 and CMIP6 multimodel mean are selected for composite analysis. Also shown are composite differences of the surface zonal wind stress (b) climatology and (e) projection, the wind stress curl (c) climatology and (f) projection, and the DSL (d) climatology and (g) projection corresponding to a more equatorward-located westerly wind stress of $2.98^{\circ}$. The multimodel averaged climatology and projection patterns are superimposed as contours. To show an equatorward displacement in the subgroup of models with the simulated westerly winds located more equatorward relative to the multimodel mean, the pink lines in (b)-(e) indicate selective contours of the corresponding fields when the multimodel mean and composite differences are added together. 

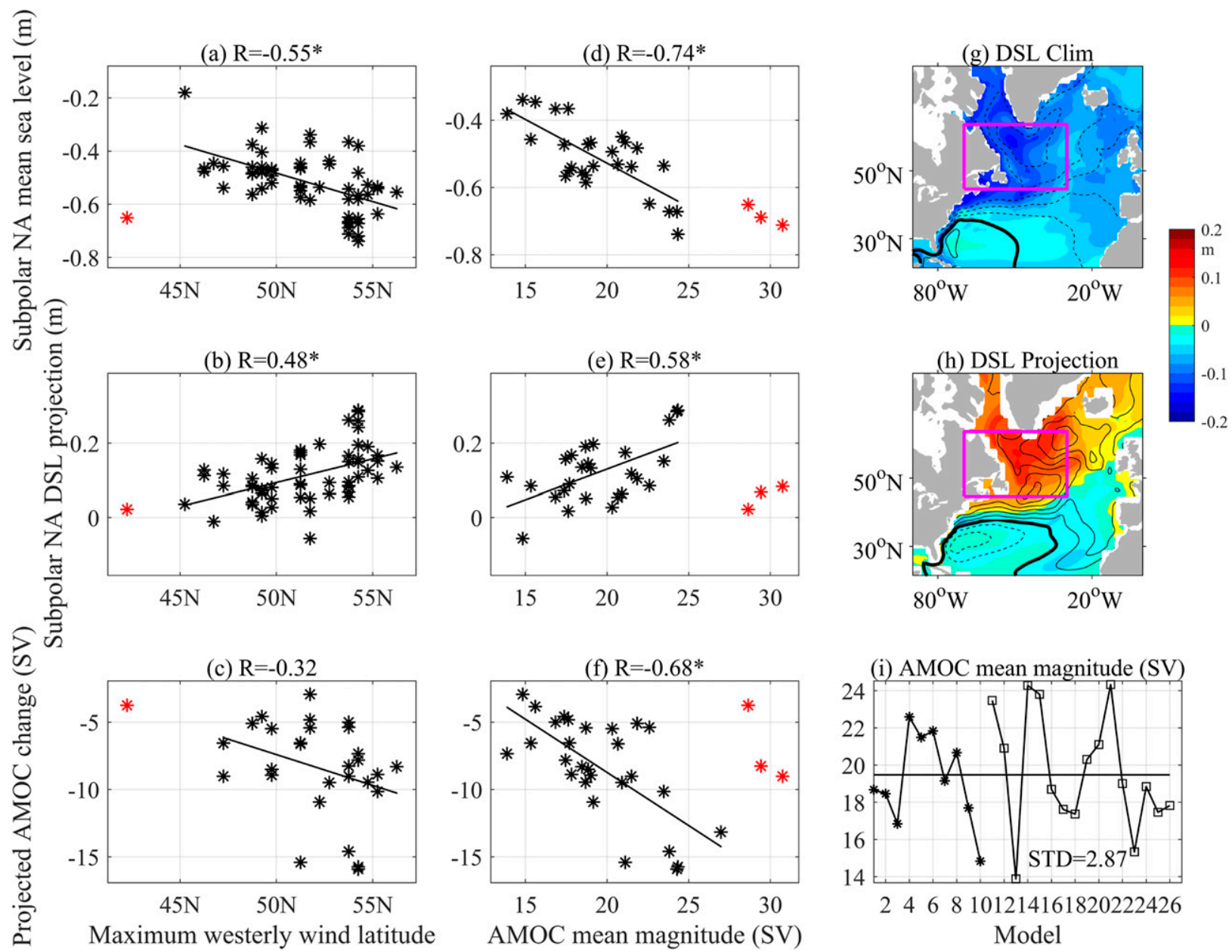

FIG. 14. (left) Scatterplots for the latitude of the maximum climatological surface westerly wind stress over the North Atlantic vs (a) the mean sea level and (b) the projected DSL changes averaged in the northwest Atlantic subpolar region $\left[45^{\circ}-60^{\circ} \mathrm{N}, 70^{\circ}-30^{\circ} \mathrm{W}\right.$; see pink box in (g) and (h)] and (c) the projected AMOC changes from the CMIP5 and CMIP6 models. (middle) As in the left column, but for scatterplots for the AMOC mean magnitude under current climatology vs (d) the mean sea level and (e) the projected DSL changes averaged in the northwest Atlantic subpolar region and (f) the projected AMOC changes. In (a)-(f), red asterisks indicate outlier models that are not included in the analysis. The black lines are linear fits. The correlations with an asterisk (*) are significant at the $95 \%$ confidence level. (right) Composite differences of the (g) mean sea level and (h) DSL projections corresponding to a stronger AMOC of $2.87 \mathrm{~Sv}$ under current climatology. (i) Models with the AMOC mean magnitude at least 0.5 standard deviation below or above the CMIP5 and CMIP6 multimodel mean are selected for composite analysis. The multimodel averaged mean sea level and DSL projection patterns in $(\mathrm{g})$ and $(\mathrm{h})$, respectively, are superimposed as contours.

across models. Therefore, our analysis suggests they are two independent factors in terms of model mean-state simulations causing the intermodel spread in future climate projections in the North Atlantic and also the Arctic region.

\section{e. General notes on the intermodel analysis}

We would like to add two notes regarding our intermodel analysis. First, it would be risky to claim a correction of future projections based on a single type of model bias as there may be other additional constraints for future projections (Wang et al. 2017). For example, in addition to mean strength of the AMOC and latitude of the westerly winds, the AMOC stability is another dynamical metric to constrain future change of the AMOC (Liu et al. 2017). Second, while our analysis is conducted in each individual region, the mean-state biases and future projections might be connected across different regions. Indeed Wang et al. (2014) suggested that origins of the model mean biases should be explored from a global perspective and a simulated weak AMOC is related to the general pattern of global SST biases. Chen et al. (2019) showed that a decline in the AMOC could cause a poleward shift of the Southern 
Ocean westerly winds. Similarly, we notice that the latitudes of the climatological westerly wind stress are well correlated $(R=0.72)$ between the North Atlantic and the Southern Ocean, suggesting that the simulated westerly winds tend to be located toward equatorward or poleward in both basins.

\section{Summary and discussions}

In this study, we evaluate climate model simulations of mean sea level against observations and examine future projections of regional DSL in both the CMIP5 and CMIP6 model ensembles. While there was a remarkable improvement from CMIP3 to CMIP5 in simulating the mean sea level (Landerer et al. 2014), there is no similar significant improvement from CMIP5 to CMIP6 as both model ensembles simulate the mean sea level well. The CMIP6 models do exhibit slightly better performance than the CMIP5 models in simulating the mean field of surface zonal wind stress. Significant differences between CMIP5 and CMIP6 are mainly found in the Southern Hemisphere middle to high latitudes in terms of both mean sea level and surface zonal wind stress simulations. The equatorward bias of the Southern Hemisphere westerly wind stress is reduced from CMIP5 to CMIP6, with fewer models showing an equatorward bias. Correspondingly, there are fewer models in CMIP6 showing significant equatorward biases in the latitudes of the maximum meridional gradient of the mean sea level in the Southern Ocean.

The CMIP6 models exhibit very similar features of regional DSL projections as the CMIP5 models. The intermodel spread is also not significantly reduced from CMIP5 to CMIP6. Nevertheless, the CMIP6 models project larger magnitudes of DSL changes compared to the CMIP5 models, mainly in the North Atlantic and Arctic associated with a larger weakening of the AMOC. We suggest that the increase of projected DSL changes in CMIP6 in the North Atlantic and Arctic is likely due to the inclusion of several CMIP6 models with a larger climate sensitivity than the upper range of climate sensitivity in the CMIP5 ensemble. A large climate sensitivity potentially could also impact other components of sea level projections, such as the global ocean heat uptake and thermal expansion, and mass loss from glaciers and ice sheets (Vega-Westhoff et al. 2020). Given that the climate sensitivity is still not well constrained and large values of climate sensitivity from the CMIP6 models cannot be ruled out, it is critical to assess the implications of a large climate sensitivity for global and regional sea level projections.

Considering the similarity of mean sea level simulations and DSL projections between the CMIP5 and CMIP6 ensembles, we combine the available CMIP5 and CMIP6 models for a further intermodel analysis to identify connections between model mean states and future projections. The common cold-tongue bias that exists in most climate models tends to induce falling DSL in the western tropical Pacific, which means a larger DSL rise is expected in this region if the effect of the cold-tongue bias is considered. In both the Southern Ocean and North Pacific, models with the climatological westerly wind stress located more equatorward tend to project a larger poleward shift of the westerly wind stress, which further induces larger magnitudes in the projected wind stress curl and DSL changes. In the North Atlantic, models with a more equatorward location of the climatological westerly wind stress or a weaker AMOC under current climatology tend to project a smaller weakening of the AMOC and smaller magnitudes of DSL changes in the North Atlantic and the coastal Arctic. These intermodel relationships between model mean-state simulations and future projections indicate that the observable mean climate states may be useful metrics for weighting models in multimodel ensemble projections or to constrain climate model projections using the concept of emergent constraints (Mote et al. 2011; Eyring et al. 2019). Our analyses also suggest the importance of reducing model mean biases in order to narrow the intermodel spread in future projections.

Our study points out the important effects of model climate sensitivity and mean-state simulations on regional DSL projections, thus providing new perspectives on how to understand and address the intermodel uncertainties in regional DSL projections. The origins of uncertainties in regional DSL projections could also be addressed from other perspectives, such as conducting model perturbation experiments following the FluxAnomaly-Forced Model Intercomparison Project (FAFMIP) protocol under either the fully coupled model framework (Gregory et al. 2016; Couldrey et al., manuscript submitted to Climate Dyn.) or the oceanonly model framework (Todd et al. 2020, manuscript submitted to J. Adv. Model. Earth Syst.). While the ocean components of most climate models analyzed here have coarse resolutions with a nominal spatial resolution of $100 \mathrm{~km}$, the High Resolution Model Intercomparison Project (HighResMIP; Haarsma et al. 2016) for CMIP6 provides a valuable opportunity to assess the impacts of model horizonal resolution on DSL projections (e.g., Zhang et al. 2017). In addition, models analyzed here still do not have an interactive ice sheet module and thus the DSL responses to the freshwater discharge from glaciers and ice sheets are not included, which is a gap potentially to be filled by making use of the simulations from the Ice Sheet Model Intercomparison Project (ISMIP6; Nowicki et al. 2016). 
Acknowledgments. This study was supported by the Centre for Southern Hemisphere Oceans Research (CSHOR), jointly funded by the Qingdao National Laboratory for Marine Science and Technology (QNLM, China) and the Commonwealth Scientific and Industrial Research Organisation (CSIRO, Australia), and the Australian Research Council's Discovery Project funding scheme (Project DP190101173). We are grateful for constructive comments from three anonymous reviewers. We also thank Dave Bi and Guojian Wang for helpful discussions. We acknowledge the World Climate Research Programme, which, through its Working Group on Coupled Modelling, coordinated and promoted CMIP. We thank the climate modelling groups (listed in Tables 1 and 2) for producing and making available their model output, the Earth System Grid Federation (ESGF) for archiving the data and providing access, and the multiple funding agencies who support CMIP and ESGF. This research was undertaken with the assistance of resources from the National Computational Infrastructure (NCI Australia), an NCRIS enabled capability supported by the Australian Government.

Data availability. The CMIP5 and CMIP6 model outputs can be accessed from https://esgf-node.llnl.gov/ projects/esgf-llnl/. The mean ocean dynamic topography data are available at http://apdrc.soest.hawaii.edu/ datadoc/mdot.php. The Scatterometer Climatology of Ocean Winds (SCOW) product can be found at http:// cioss.coas.oregonstate.edu/scow/. The ERA5 data can be downloaded from the Copernicus Climate Change Service (C3S) Climate Data Store (https://doi.org/10.24381/ cds.f17050d7).

\section{REFERENCES}

Årthun, M., T. Eldevik, and L. H. Smedsrud, 2019: The role of Atlantic heat transport in future Arctic winter sea ice loss. J. Climate, 32, 3327-3341, https://doi.org/10.1175/JCLI-D-18-0750.1.

Barnes, E. A., and D. L. Hartmann, 2010: Testing a theory for the effect of latitude on the persistence of eddy-driven jets using CMIP3 simulations. Geophys. Res. Lett., 37, L15801, https:// doi.org/10.1029/2010GL044144.

— , and L. Polvani, 2013: Response of the midlatitude jets, and of their variability, to increased greenhouse gases in the CMIP5 models. J. Climate, 26, 7117-7135, https://doi.org/10.1175/JCLI-D-12-00536.1.

- D. L. Hartmann, D. M. Frierson, and J. Kidston, 2010: Effect of latitude on the persistence of eddy-driven jets. Geophys. Res. Lett., 37, L11804, https://doi.org/10.1029/2010GL043199.

Belmonte Rivas, M., and A. Stoffelen, 2019: Characterizing ERAInterim and ERA5 surface wind biases using ASCAT. Ocean Sci., 15, 831-852, https://doi.org/10.5194/os-15-831-2019.

Bouttes, N., and J. M. Gregory, 2014: Attribution of the spatial pattern of $\mathrm{CO}_{2}$-forced sea level change to ocean surface flux changes. Environ. Res. Lett., 9, 034004, https://doi.org/10.1088/ 1748-9326/9/3/034004.

— - — , T. Kuhlbrodt, and T. Suzuki, 2012: The effect of windstress change on future sea level change in the Southern
Ocean. Geophys. Res. Lett., 39, L23602, https://doi.org/10.1029/ 2012GL054207.

,--1, - - and R. S. Smith, 2014: The drivers of projected North Atlantic sea level change. Climate Dyn., 43, 1531-1544, https://doi.org/10.1007/s00382-013-1973-8.

Bracegirdle, T. J., E. Shuckburgh, J.-B . Sallee, Z. Wang, A. J. S. Meijers, N. Bruneau, T. Phillips, and L. J. Wilcox, 2013: Assessment of surface winds over the Atlantic, Indian, and Pacific Ocean sectors of the Southern Ocean in CMIP5 models: Historical bias, forcing response, and state dependence. J. Geophys. Res. Atmos., 118, 547-562, https://doi.org/ 10.1002/jgrd.50153.

Brown, J. N., R. J. Matear, J. R. Brown, and J. Katzfey, 2015: Precipitation projections in the tropical Pacific are sensitive to different types of SST bias adjustment. Geophys. Res. Lett., $\mathbf{4 2}$, 10 856-10 866, https://doi.org/10.1002/2015GL066184.

Bryan, K., 1996: The steric component of sea level rise associated with enhanced greenhouse warming: A model study. Climate Dyn., 12, 545-555, https://doi.org/10.1007/BF00207938.

Cai, W., and T. Cowan, 2013: Why is the amplitude of the Indian Ocean dipole overly large in CMIP3 and CMIP5 climate models? Geophys. Res. Lett., 40, 1200-1205, https://doi.org/10.1002/grl.50208.

Carson, M., A. Köhl, and D. Stammer, 2015: The impact of regional multidecadal and century-scale internal climate variability on sea level trends in CMIP5 models. J. Climate, 28, 853-861, https://doi.org/10.1175/JCLI-D-14-00359.1.

- K. Lyu, K. Richter, M. Becker, C. M. Domingues, W. Han, and L. Zanna, 2019: Climate model uncertainty and trend detection in regional sea level projections: A review. Surv. Geophys., 40, 1631-1653, https://doi.org/10.1007/s10712-019-09559-3.

Chelton, D. B., and M. H. Freilich, 2005: Scatterometer-based assessment of 10-m wind analyses from the operational ECMWF and NCEP numerical weather prediction models. Mon. Wea. Rev., 133, 409-429, https://doi.org/10.1175/MWR-2861.1.

Chen, C., W. Liu, and G. Wang, 2019: Understanding the uncertainty in the 21st century dynamic sea level projections: The role of the AMOC. Geophys. Res. Lett., 46, 210-217, https:// doi.org/10.1029/2018GL080676.

Church, J. A., and Coauthors, 2013: Sea level change. Climate Change 2013: The Physical Science Basis, T. F. Stocker et al., Eds., Cambridge University Press, 1137-1216.

Csanady, G. T., 1978: The arrested topographic wave. J. Phys. Oceanogr., 8, 47-62, https://doi.org/10.1175/1520-0485(1978) $008<0047$ :TATW $>2.0$. CO; 2

England, M. H., and Coauthors, 2014: Recent intensification of wind-driven circulation in the Pacific and the ongoing warming hiatus. Nat. Climate Change, 4, 222-227, https://doi.org/ 10.1038/nclimate2106.

Eyring, V., S. Bony, G. A. Meehl, C. A. Senior, B. Stevens, R. J. Stouffer, and K. E. Taylor, 2016: Overview of the Coupled Model Intercomparison Project Phase 6 (CMIP6) experimental design and organization. Geosci. Model Dev., 9, 19371958, https://doi.org/10.5194/gmd-9-1937-2016.

_ - and Coauthors, 2019: Taking climate model evaluation to the next level. Nat. Climate Change, 9, 102-110, https://doi.org/ 10.1038/s41558-018-0355-y.

Fasullo, J. T., and R. S. Nerem, 2018: Altimeter-era emergence of the patterns of forced sea-level rise in climate models and implications for the future. Proc. Natl. Acad. Sci. USA, 115, 12 944-12 949, https://doi.org/10.1073/pnas.1813233115.

Flato, G. J., and Coauthors, 2013: Evaluation of climate models. Climate Change 2013: The Physical Science Basis, T. F. Stocker et al., Eds., Cambridge University Press, 741-866-. 
Fyfe, J. C., and O. A. Saenko, 2006: Simulated changes in the extratropical Southern Hemisphere winds and currents. Geophys. Res. Lett., 33, L06701, https://doi.org/10.1029/2005GL025332.

Gregory, J. M., and J. A. Lowe, 2000: Predictions of global and regional sea-level rise using AOGCMs with and without flux adjustment. Geophys. Res. Lett., 27, 3069-3072, https://doi.org/ 10.1029/1999GL011228.

_- and Coauthors, 2001: Comparison of results from several AOGCMs for global and regional sea-level change 1900-2100. Climate Dyn., 18, 225-240, https://doi.org/10.1007/s003820100180.

- and Coauthors, 2004: A new method for diagnosing radiative forcing and climate sensitivity. Geophys. Res. Lett., 31, L03205, https://doi.org/10.1029/2003GL018747.

_- and Coauthors, 2005: A model intercomparison of changes in the Atlantic thermohaline circulation in response to increasing atmospheric $\mathrm{CO}_{2}$ concentration. Geophys. Res. Lett., 32, L12703, https://doi.org/10.1029/2005GL023209.

_ , and Coauthors, 2016: The Flux-Anomaly-Forced Model Intercomparison Project (FAFMIP) contribution to CMIP6: Investigation of sea-level and ocean climate change in response to $\mathrm{CO}_{2}$ forcing. Geosci. Model Dev., 9, 3993-4017, https://doi.org/10.5194/gmd-9-3993-2016.

— , and Coauthors, 2019: Concepts and terminology for sea level: Mean, variability and change, both local and global. Surv. Geophys. 40, 1251-1289, https://doi.org/10.1007/s10712-019-09525-z.

Griffies, S. M., and Coauthors, 2016: OMIP contribution to CMIP6: Experimental and diagnostic protocol for the physical component of the Ocean Model Intercomparison Project. Geosci. Model Dev., 9, 3231-3296, https://doi.org/10.5194/gmd-9-32312016.

Grose, M. R., J. Gregory, R. Colman, and T. Andrews, 2018: What climate sensitivity index is most useful for projections? Geophys. Res. Lett., 45, 1559-1566, https://doi.org/10.1002/ 2017 GL075742.

_ - and Coauthors, 2020: Insights from CMIP6 for Australia's future climate. Earth's Future, 8, e2019EF001469, https:// doi.org/10.1029/2019EF001469.

Haarsma, R. J., and Coauthors, 2016: High Resolution Model Intercomparison Project (HighResMIP v1.0) for CMIP6. Geosci. Model Dev., 9, 4185-4208, https://doi.org/10.5194/ gmd-9-4185-2016.

Ham, Y. G., and J. S. Kug, 2015: Improvement of ENSO simulation based on intermodel diversity. J. Climate, 28, 998-1015, https:// doi.org/10.1175/JCLI-D-14-00376.1.

Hamlington, B. D., M. W. Strassburg, R. R. Leben, W. Han, R. S. Nerem, and K. Y. Kim, 2014: Uncovering an anthropogenic sea-level rise signal in the Pacific Ocean. Nat. Climate Change, 4, 782-785, https://doi.org/10.1038/nclimate2307.

Hersbach, H., and D. Dee, 2016: ERA5 reanalysis is in production. ECMWF Newsletter, No. 147, ECMWF, Reading, United Kingdom, 7, http://www.ecmwf.int/sites/default/files/elibrary/ 2016/16299-newsletter-no147-spring-2016.pdf.

Hobbs, W., M. D. Palmer, and D. Monselesan, 2016: An energy conservation analysis of ocean drift in the CMIP5 global coupled models. J. Climate, 29, 1639-1653, https://doi.org/ 10.1175/JCLI-D-15-0477.1.

Huang, P., and J. Ying, 2015: A multimodel ensemble pattern regression method to correct the tropical Pacific SST change patterns under global warming. J. Climate, 28, 4706-4723, https://doi.org/10.1175/JCLI-D-14-00833.1.

Huber, M. B., and L. Zanna, 2017: Drivers of uncertainty in simulated ocean circulation and heat uptake. Geophys. Res. Lett., 44, 1402-1413, https://doi.org/10.1002/2016GL071587.
Hughes, C. W., I. Fukumori, S. M. Griffies, J. M. Huthnance, S. Minobe, P. Spence, K. R. Thompson, and A. Wise, 2019: Sea level and the role of coastal trapped waves in mediating the influence of the open ocean on the coast. Surv. Geophys., 40, 1467-1492, https://doi.org/10.1007/s10712-019-09535-x.

Kidston, J., and E. P. Gerber, 2010: Intermodel variability of the poleward shift of the austral jet stream in the CMIP3 integrations linked to biases in 20th century climatology. Geophys. Res. Lett., 37, L09708, https://doi.org/10.1029/2010GL042873.

Kuhlbrodt, T., and J. M. Gregory, 2012: Ocean heat uptake and its consequences for the magnitude of sea level rise and climate change. Geophys. Res. Lett., 39, L18608, https://doi.org/10.1029/ 2012GL052952.

- R. S. Smith, Z. Wang, and J. M. Gregory, 2012: The influence of eddy parameterizations on the transport of the Antarctic Circumpolar Current in coupled climate models. Ocean Modell., 52-53, 1-8, https://doi.org/10.1016/j.ocemod.2012.04.006.

Landerer, F. W., J. H. Jungclaus, and J. Marotzke, 2007: Regional dynamic and steric sea level change in response to the IPCC-A1B scenario. J. Phys. Oceanogr., 37, 296-312, https://doi.org/10.1175/JPO3013.1.

_ P. J. Gleckler, and T. Lee, 2014: Evaluation of CMIP5 dynamic sea surface height multi-model simulations against satellite observations. Climate Dyn., 43, 1271-1283, https:// doi.org/10.1007/s00382-013-1939-x.

Lee, T., D. E. Waliser, J. L. F. Li, F. W. Landerer, and M. M. Gierach, 2013: Evaluation of CMIP3 and CMIP5 wind stress climatology using satellite measurements and atmospheric reanalysis products. J. Climate, 26, 5810-5826, https://doi.org/ 10.1175/JCLI-D-12-00591.1.

Li, G., and S. P. Xie, 2014: Tropical biases in CMIP5 multimodel ensemble: The excessive equatorial Pacific cold tongue and double ITCZ problems. J. Climate, 27, 1765-1780, https:// doi.org/10.1175/JCLI-D-13-00337.1.

,,-- Y. Du, and Y. Luo, 2016: Effects of excessive equatorial cold tongue bias on the projections of tropical Pacific climate change. Part I: The warming pattern in CMIP5 multi-model ensemble. Climate Dyn., 47, 3817-3831, https://doi.org/10.1007/ s00382-016-3043-5.

Liu, W., S. P. Xie, Z. Liu, and J. Zhu, 2017: Overlooked possibility of a collapsed Atlantic meridional overturning circulation in warming climate. Sci. Adv., 3, e1601666, https://doi.org/ 10.1126/sciadv.1601666.

Lowe, J. A., and J. M. Gregory, 2006: Understanding projections of sea level rise in a Hadley Centre coupled climate model. J. Geophys. Res., 111, C11014, https://doi.org/10.1029/2005JC003421.

Lyu, K., X. Zhang, J. A. Church, A. B. Slangen, and J. Hu, 2014: Time of emergence for regional sea-level change. Nat. Climate Change, 4, 1006-1010, https://doi.org/10.1038/nclimate2397.

$-, \ldots,-$, and J. Hu, 2015: Quantifying internally generated and externally forced climate signals at regional scales in CMIP5 models. Geophys. Res. Lett., 42, 9394-9403, https:// doi.org/10.1002/2015GL065508.

,,,--- and,- 2016 : Evaluation of the interdecadal variability of sea surface temperature and sea level in the Pacific in CMIP3 and CMIP5 models. Int. J. Climatol., 36, 3723-3740, https://doi.org/10.1002/joc. 4587.

,,,$----\frac{1}{-}$, and J. Y. Yu, 2017: Distinguishing the quasidecadal and multidecadal sea level and climate variations in the Pacific: Implications for the ENSO-like low-frequency variability. J. Climate, 30, 5097-5117, https://doi.org/10.1175/ JCLI-D-17-0004.1.

,$--\frac{}{-}$, and Q. Wu, 2020: Processes responsible for the Southern Hemisphere ocean heat uptake and redistribution 
under anthropogenic warming. J. Climate, 33, 3787-3807, https://doi.org/10.1175/JCLI-D-19-0478.1.

Maximenko, N., P. Niiler, L. Centurioni, M. Rio, O. Melnichenko, D. Chambers, V. Zlotnicki, and B. Galperin, 2009: Mean dynamic topography of the ocean derived from satellite and drifting buoy data using three different techniques. J. Atmos. Oceanic Technol., 26, 1910-1919, https://doi.org/10.1175/2009JTECHO672.1.

Meehl, G. A., and Coauthors, 2007: Global climate projections. Climate Change 2007: The Physical Science Basis, S. Solomon et al., Eds., Cambridge University Press, 747-845.

Meijers, A. J., E. Shuckburgh, N. Bruneau, J. B. Sallee, T. J. Bracegirdle, and Z. Wang, 2012: Representation of the Antarctic Circumpolar Current in the CMIP5 climate models and future changes under warming scenarios. J. Geophys. Res., 117, C12008, https://doi.org/10.1029/2012JC008412.

Morim, J., M. Hemer, F. Andutta, T. Shimura, and N. Cartwright, 2020: Skill and uncertainty in surface wind fields from general circulation models: Intercomparison of bias between AGCM, AOGCM and ESM global simulations. Int. J. Climatol., 40, 2659-2673, https://doi.org/10.1002/joc.6357.

Mote, P., L. Brekke, P. B. Duffy, and E. Maurer, 2011: Guidelines for constructing climate scenarios. Eos, Trans. Amer. Geophys. Union, 92, 257-258, https://doi.org/10.1029/2011EO310001.

Nowicki, S. M., and Coauthors, 2016: Ice Sheet Model Intercomparison Project (ISMIP6) contribution to CMIP6. Geosci. Model Dev., 9, 4521-4545, https://doi.org/10.5194/gmd-9-4521-2016.

O'Neill, B. C., and Coauthors, 2016: The Scenario Model Intercomparison Project (ScenarioMIP) for CMIP6. Geosci. Model Dev., 9, 3461-3482, https://doi.org/10.5194/gmd-9-3461-2016.

Oppenheimer, M., and Coauthors, 2019: Sea level rise and implications for low-lying islands, coasts and communities. IPCC Special Report on the Ocean and Cryosphere in a Changing Climate, H.-O. Pörtner et al., Eds., Cambridge University Press, https:// www.ipcc.ch/srocc/chapter/chapter-4-sea-level-rise-and-implications-for-low-lying-islands-coasts-and-communities/, in press.

Palanisamy, H., B. Meyssignac, A. Cazenave, and T. Delcroix, 2015: Is anthropogenic sea level fingerprint already detectable in the Pacific Ocean? Environ. Res. Lett., 10, 084024, https:// doi.org/10.1088/1748-9326/10/8/084024.

Pardaens, A. K., J. M. Gregory, and J. A. Lowe, 2011: A model study of factors influencing projected changes in regional sea level over the twenty-first century. Climate Dyn., 36, 20152033, https://doi.org/10.1007/s00382-009-0738-x.

Riahi, K., and Coauthors, 2017: The shared socioeconomic pathways and their energy, land use, and greenhouse gas emissions implications: An overview. Global Environ. Change, 42, 153168, https://doi.org/10.1016/j.gloenvcha.2016.05.009.

Risien, C. M., and D. B. Chelton, 2008: A global climatology of surface wind and wind stress fields from eight years of QuikSCAT scatterometer data. J. Phys. Oceanogr., 38, 23792413, https://doi.org/10.1175/2008JPO3881.1.

Russell, J. L., K. W. Dixon, A. Gnanadesikan, R. J. Stouffer, and J. R. Toggweiler, 2006: The Southern Hemisphere westerlies in a warming world: Propping open the door to the deep ocean. J. Climate, 19, 6382-6390, https://doi.org/10.1175/JCLI3984.1.

Sallée, J. B., E. Shuckburgh, N. Bruneau, A. J. Meijers, T. J. Bracegirdle, Z. Wang, and T. Roy, 2013: Assessment of Southern Ocean water mass circulation and characteristics in CMIP5 models: Historical bias and forcing response. J. Geophys. Res. Oceans, 118, 1830-1844, https://doi.org/10.1002/jgrc.20135.
Sen Gupta, A., N. C. Jourdain, J. N. Brown, and D. Monselesan, 2013: Climate drift in the CMIP5 models. J. Climate, 26, 85978615, https://doi.org/10.1175/JCLI-D-12-00521.1.

Suzuki, T., and M. Ishii, 2011: Regional distribution of sea level changes resulting from enhanced greenhouse warming in the Model for Interdisciplinary Research on Climate version 3.2. Geophys. Res. Lett., 38, L02601, https://doi.org/10.1029/ 2010 GL045693.

, and Coauthors, 2005: Projection of future sea level and its variability in a high-resolution climate model: Ocean processes and Greenland and Antarctic ice-melt contributions. Geophys. Res. Lett., 32, L19706, https://doi.org/10.1029/ 2005 GL023677.

Swart, N. C., and J. C. Fyfe, 2012: Observed and simulated changes in the Southern Hemisphere surface westerly wind-stress. Geophys. Res. Lett., 39, L16711, https://doi.org/10.1029/ 2012GL052810.

— , and Coauthors, 2019: The Canadian Earth System Model version 5 (CanESM5. 0.3). Geosci. Model Dev., 12, 4823-4873, https://doi.org/10.5194/gmd-12-4823-2019.

van Vuuren, D. P., and Coauthors, 2011: The representative concentration pathways: An overview. Climatic Change, 109, 5-31, https://doi.org/10.1007/s10584-011-0148-z.

Vega-Westhoff, B., R. L. Sriver, C. Hartin, T. E. Wong, and K. Keller, 2020: The role of climate sensitivity in upper-tail sea level rise projections. Geophys. Res. Lett., 47, e2019GL085792, https://doi.org/10.1029/2019GL085792.

Wang, C., L. Zhang, S. K. Lee, L. Wu, and C. R. Mechoso, 2014: A global perspective on CMIP5 climate model biases. Nat. Climate Change, 4, 201-205, https://doi.org/10.1038/nclimate2118.

Wang, G., W. Cai, and A. Santoso, 2017: Assessing the impact of model biases on the projected increase in frequency of extreme positive Indian Ocean dipole events. J. Climate, 30, 2757-2767, https://doi.org/10.1175/JCLI-D-16-0509.1.

Yin, J., 2012: Century to multi-century sea level rise projections from CMIP5 models. Geophys. Res. Lett., 39, L17709, https:// doi.org/10.1029/2012GL052947.

—, M. E. Schlesinger, and R. J. Stouffer, 2009: Model projections of rapid sea-level rise on the northeast coast of the United States. Nat. Geosci., 2, 262-266, https://doi.org/10.1038/ngeo462.

_ S. M. Griffies, and R. J. Stouffer, 2010: Spatial variability of sea level rise in twenty-first century projections. J. Climate, 23, 4585-4607, https://doi.org/10.1175/2010JCLI3533.1.

Zelinka, M. D., T. A. Myers, D. T. McCoy, S. Po-Chedley, P. M. Caldwell, P. Ceppi, S. A. Klein, and K. E. Taylor, 2020: Causes of higher climate sensitivity in CMIP6 models. Geophys. Res. Lett., 47, e2019GL085782, https://doi.org/10.1029/ 2019GL085782.

Zhang, X., and J. A. Church, 2012: Sea level trends, interannual and decadal variability in the Pacific Ocean. Geophys. Res. Lett., 39, L21701, https://doi.org/10.1029/2012GL053240.

-, S. M. Platten, and D. Monselesan, 2014: Projection of subtropical gyre circulation and associated sea level changes in the Pacific based on CMIP3 climate models. Climate Dyn., 43, 131-144, https://doi.org/10.1007/s00382-013-1902-x.

- — - D. Monselesan, and K. L. McInnes, 2017: Sea level projections for the Australian region in the 21st century. Geophys. Res. Lett., 44, 8481-8491, https://doi.org/10.1002/ 2017 GL074176. 